\title{
Las designaciones judiciales en la presidencia de Mauricio Macri
}

\author{
Candela Villalibre y José Ignacio López ${ }^{2}$ \\ Universidad Nacional de La Plata - Argentina
}

Revista Derechos en Acción ISSN 2525-1678/ e-ISSN 2525-1686

Año 5/No 14, Verano 2019-2020 (21 diciembre a 20 marzo), 786-828

DOI: https://doi.org/10.24215/25251678e376

ORCID: https://orcid.org/0000-0003-2308-8933

https://orcid.org/0000-0002-2836-8697

\section{Introducción}

En Argentina, durante el Gobierno de Mauricio MACRI, el Poder Judicial ocupó un espacio central en la agenda mediática. En ese contexto, un análisis de las designaciones de cargos de la magistratura realizadas durante su mandato, permite observar cómo queda diseñado el mapa judicial de cara a la gestión entrante de Alberto Fernández.

A modo introductorio cabe recordar que, a pesar de que luego el ex presidente diera marcha atrás, los nombramientos por decreto y "en comisión" de los jueces de la Corte Suprema de Justicia, Carlos Rosenkrantz y Horacio RosatTi, constituyeron uno de los aspectos más resonantes.

\footnotetext{
Abogada (UNLP). Periodista (TEA). Docente en la Diplomatura en Comunicación Judicial (UNLZ). Integra el equipo del portal jurídico "Palabras del Derecho" (www.palabrasdelderecho.com.ar).

2 Abogado (UNLP). Docente de Derecho Administrativo II en la Facultad de Ciencias Jurídicas y Sociales y de Derecho de la Comunicación en la Facultad de Periodismo y Comunicación Social, ambas de la Universidad Nacional de La Plata. Director del portal jurídico "Palabras del Derecho" (www.palabrasdelderecho.com.ar).
} 
Asimismo, el traslado estratégico de magistrados de un juzgado a otro motivó a que el Consejo de la Magistratura, al cierre de éste período, sancionara un reglamento más riguroso para la aprobación de los pases de tribunal ${ }^{3}$.

Por otra parte, aún persisten en la mayor parte del país desigualdades entre hombres y mujeres en cuanto a la composición de los diferentes organismos y rangos ${ }^{4}$.

Este breve trabajo de investigación se propone el análisis cuantitativo de las designaciones realizadas durante los últimos cuatro años en el Poder Judicial, en el Ministerio Público de la Defensa y en el Ministerio Público Fiscal. Los datos estadísticos obtenidos -producto de una muestra de cuatro años ${ }^{5}$ - reflejan cómo quedó compuesto el escenario judicial al cierre de un período ejecutivo constitucional.

\section{Los nombramientos en números}

De un total de 287 nombramientos que se realizaron durante la presidencia de Mauricio MACRI, 223 fueron en el Poder Judicial, mientras que hubo 35 en el Ministerio Público de la Defensa y 29 en el Ministerio Público Fiscal.

El 2018 fue el año en el que más designaciones se hicieron en el poder encargado de administrar Justicia: hubo 97.

\footnotetext{
3 Se trata de la Resolución 270/2019 de Consejo de la Magistratura, publicada en el Boletín Oficial el 9 de octubre de 2019, que modificó el Reglamento de Traslado de Magistrados. La nueva norma, iniciativa del Consejero por los Jueces Alberto Lugones, establece un criterio más riguroso para disponer los traslados, en especial, en cuanto a las mayorías políticas exigidas para autorizarlo.

4 Véase el trabajo de Gastiazoro, María Eugenia, “Género y trabajo: mujeres en el poder judicial", publicado por Centro de Estudios Avanzados de la UNC, 2013. Disponible en línea.

5 Este trabajo contó con la elaboración propia de la muestra de los nombramientos judiciales a través del seguimiento permanente al Boletín Oficial de la República Argentina.
} 


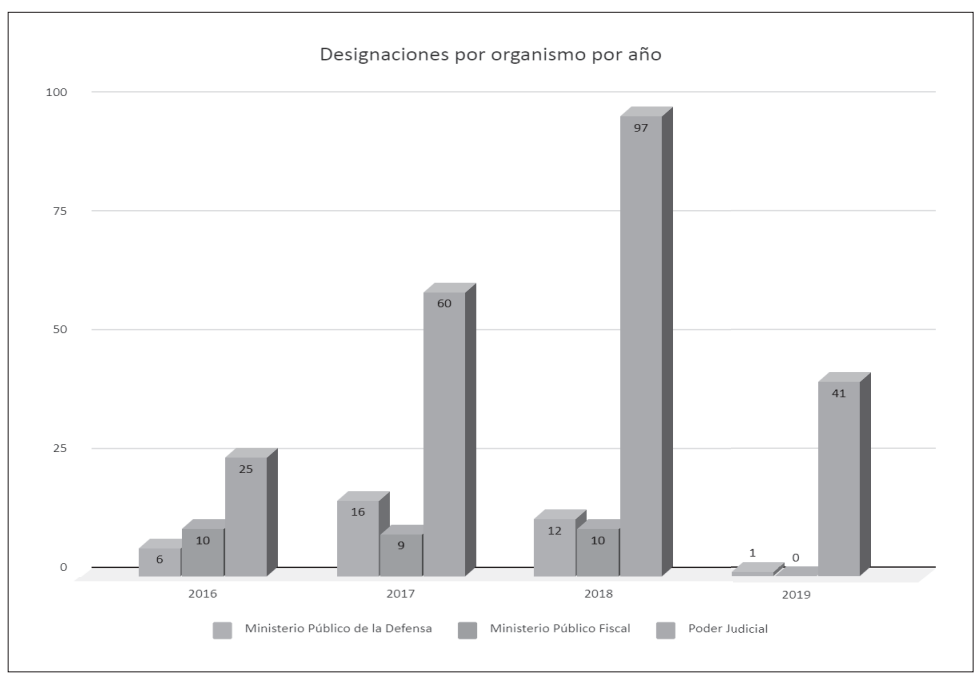

Por otra parte, la brecha de género se acentúa más en el ámbito federal donde el $78 \%$ de las personas designadas fueron hombres y el $22 \%$ mujeres.

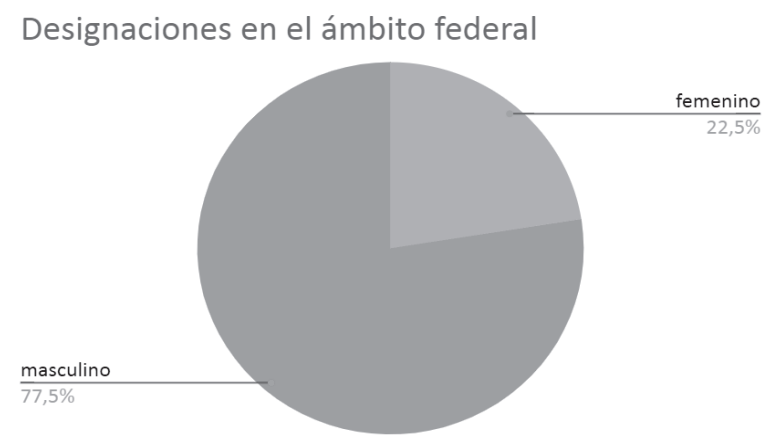

En cambio, el escenario en la Jurisdicción Nacional fue más equitativo: $51 \%$ hombres y $49 \%$ mujeres. En conclusión, del total de las designaciones realizadas y en base al criterio binario que reflejan los datos publicados en el Boletín Oficial, el $67 \%$ de los nombramientos fueron para hombres, mientras que solo el $33 \%$ fue para la representación femenina. 


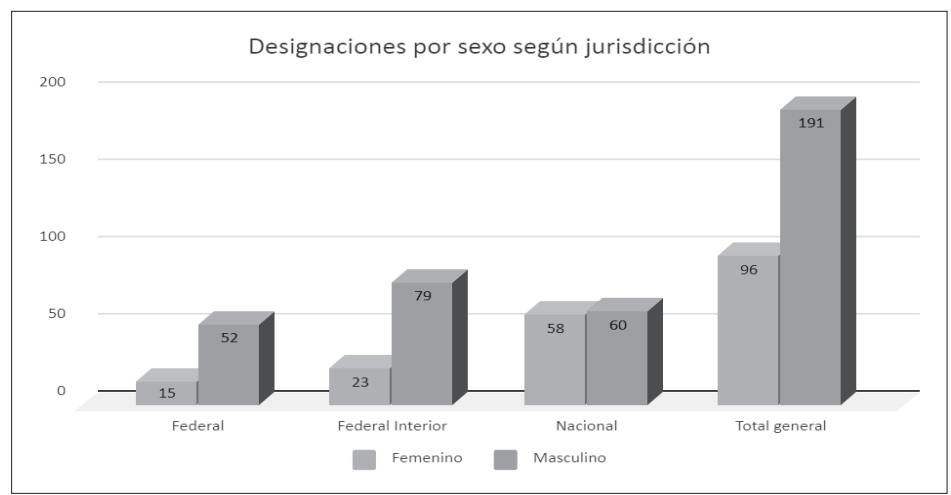

Designaciones por sexo en el ámbito federal,federal interior y Nacional

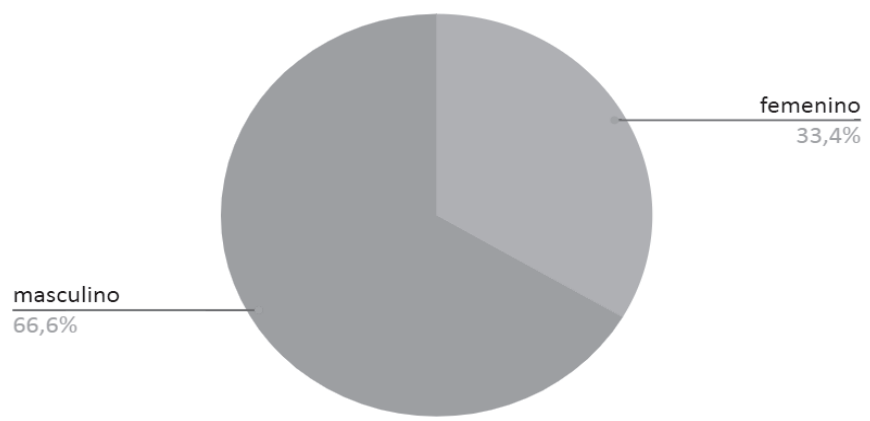

\section{III. ¿Cómo se distribuyeron las designaciones en todo el país?}

En cuanto al territorio, la Ciudad Autónoma de Buenos Aires concentró el 61 \% de las designaciones -fenómeno que se explica por el volumen de la Justicia Nacional y la concentración en esa ciudad de diversos fueros federales especializados-, seguida por la provincia bonaerense con el $10 \%$. En el tercer lugar se ubica Santa Fe con el 5 \%, luego continúa Córdoba con el $3 \%$.

Formosa, La Rioja y Santa Cruz solo contaron con 1 nombramiento cada una. 


\begin{tabular}{|l|c|}
\hline \multicolumn{1}{|c|}{ Provincias } & $\begin{array}{c}\text { Cantidad de } \\
\text { nombramientos }\end{array}$ \\
\hline Corrientes & 3 \\
\hline Chaco & 5 \\
\hline Entre Ríos & 4 \\
\hline Misiones & 29 \\
\hline Buenos Aires & 3 \\
\hline Santiago Del Estero & 2 \\
\hline San Luis & 3 \\
\hline San Juan & 5 \\
\hline Salta & 10 \\
\hline Mendoza & 1 \\
\hline La Rioja & 2 \\
\hline La Pampa & 2 \\
\hline Jujuy & 2 \\
\hline Catamarca & 1 \\
\hline Santa Cruz & 2 \\
\hline Río Negro & 4 \\
\hline Chubut & 176 \\
\hline CABA & 9 \\
\hline Córdoba & 1 \\
\hline Formosa & 13 \\
\hline Santa Fe & 3 \\
\hline Neuquén & 0 \\
\hline Tucumán & \\
\hline Tierra Del Fuego, \\
Antártida E Islas D \\
el Atlántico Sur
\end{tabular}

Por otra parte, el $41 \%$ de los nombramientos fueron para la Justicia Nacional, mientras que el $36 \%$ fueron para la jurisdicción federal del interior y el $23 \%$ restante en la federal de la Ciudad Autónoma de Buenos Aires. 


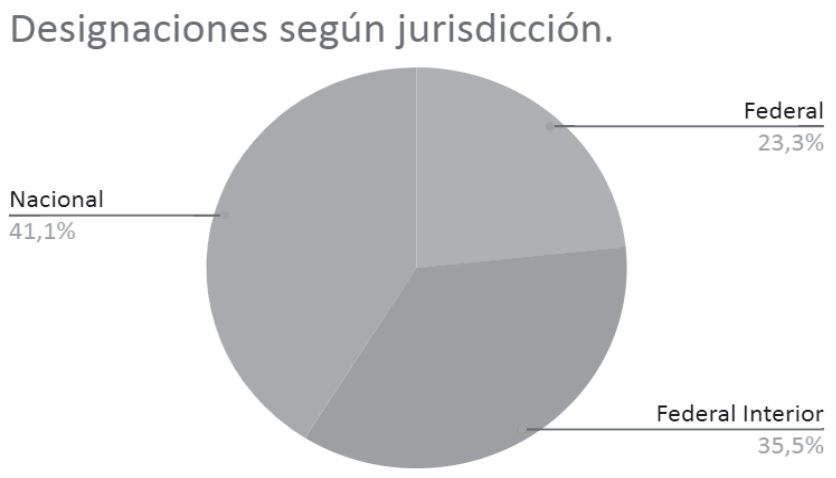

\section{IV. ¿Cómo se distribuyen los rangos en las designaciones?}

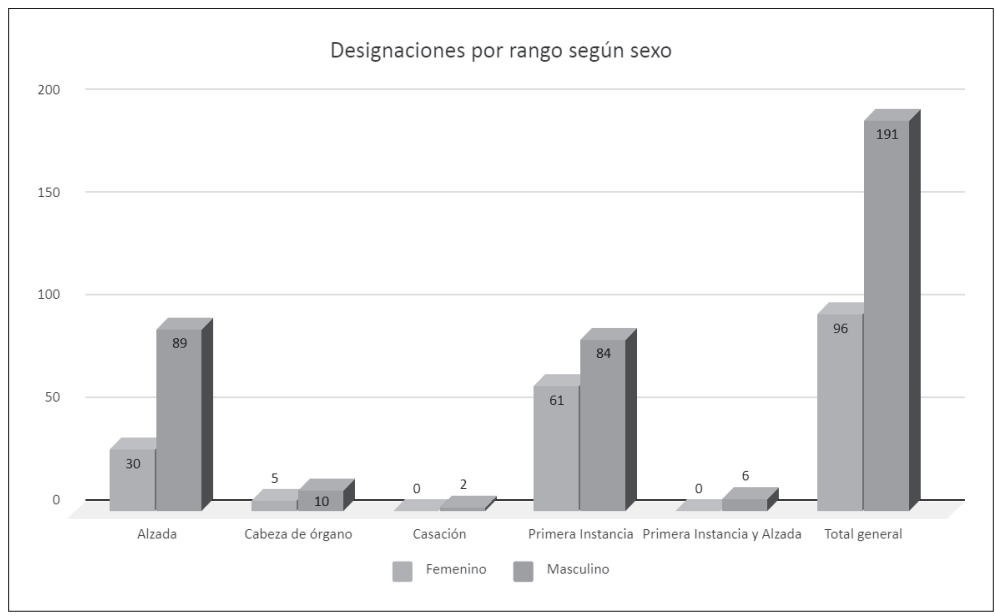

Al analizar los rangos de las designaciones se observa una notoria desigualdad de género en la distribución de los cargos de poder. De los 287 nombramientos, 145 tuvieron lugar en la Primera Instancia: de ese total el $58 \%$ está compuesto por hombres y el $42 \%$ por mujeres.

La diferencia es aún más acentuada en los organismos de Alzada: de un total de 119 designaciones el $75 \%$ fueron para hombres y el $25 \%$ para mujeres. 
En cuanto a las designaciones de cargos jerárquicos en el Ministerio Público Fiscal y en el Ministerio Público de la Defensa: la distribución es de 10 y 5, respectivamente.

En la Cámara Federal de Casación Penal los dos nombramientos realizados también fueron para hombres.

\section{Traslados}

Otro tema central en materia judicial -durante el periodo estudiado- fue el traslado de magistrados, es decir, derivar a un juez de un tribunal a otro diverso al que fue designado originariamente. Dicha maniobra, no exenta de objeciones constitucionales $^{6}$, cuenta con un reglamento del Consejo de la Magistratura $\mathrm{N}^{\circ} 155 / 2000^{7}$ que, en 2019 , fue modificado para establecer un criterio (un tanto) más riguroso.

En este rubro, los datos fueron:

- De un total de 15 traslados 3 tuvieron lugar en el 2016, 3 en el 2017 y 9 en el 2018;

- Los 15 traslados son de hombres;

- $\quad$ EL 73 \% de los traslados se concentraron en la Ciudad Autónoma de Buenos aires;

- $\quad$ El 67 \% tuvo lugar en la Justicia Federal.

\section{Los nombramientos en el Ministerio Público de la Defensa}

Durante los últimos cuatro años hubo 35 designaciones en el Ministerio Público de la Defensa. La mayor cantidad de nombramientos se produjeron durante el 2017. El $71 \%$

\footnotetext{
6 Algunos aspectos, también aplicables a los traslados, los desarrollamos en LóPEZ, José Ignacio, "La transformación de jueces. Una maniobra al margen del procedimiento constitucional de designación de magistrados". Artículo de doctrina publicado en el Diario Constitucional y Derechos Humanos No 183/184 de Derecho Para Innovar, el 9 y 16 de abril de 2018, disponible en línea.
}

7 Véase al respecto lo dicho en la nota 1 de este trabajo. 
corresponde a personas de sexo masculino y el $29 \%$ al sexo femenino.

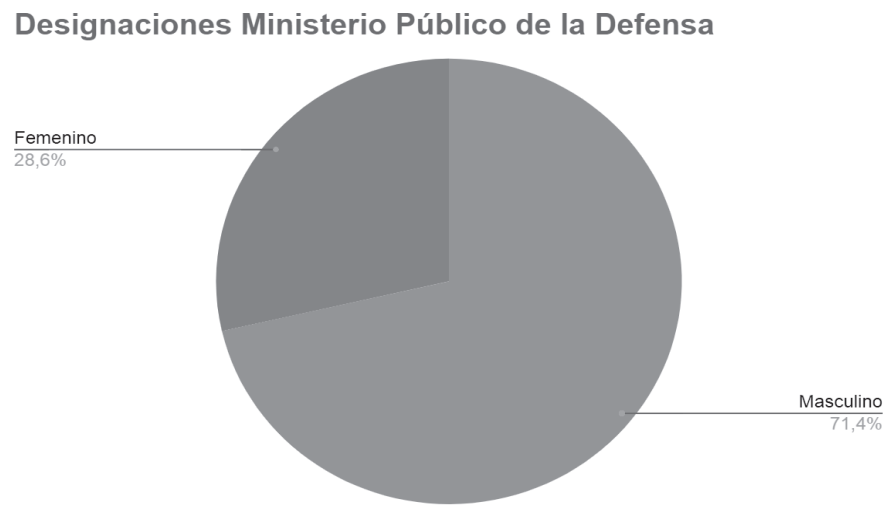

El $51 \%$ de los nombramientos se concentraron en la primera instancia, el $27 \%$ fueron para actuar ante organismos de Alzada y el $17 \%$ para actuar tanto en primera instancia como en segunda en forma simultánea (caso de defensores oficiales).

Por otra parte, el $63 \%$ de las designaciones fueron en la jurisdicción federal del interior, el $11 \%$ en el ámbito federal de la CABA y el $12 \%$ en la Justicia Nacional.

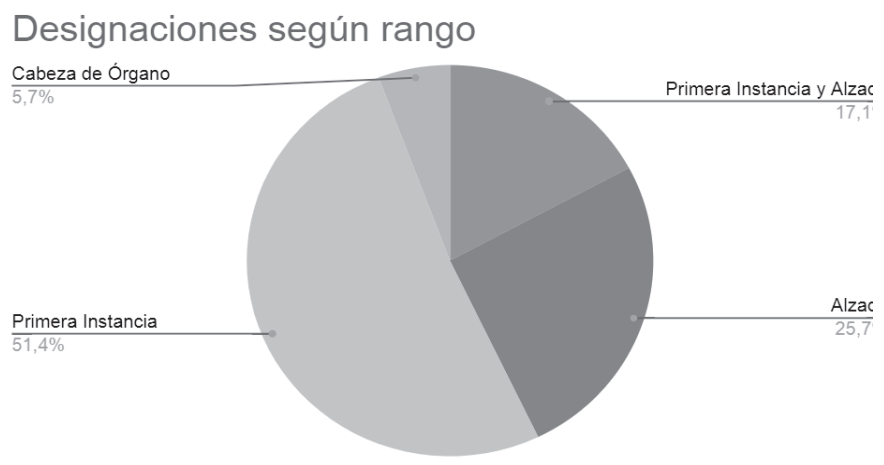




\section{Designaciones en el Ministerio Público Fiscal}

En el caso del Ministerio Público Fiscal hubo 29 designaciones durante el gobierno de M. Macri. El 69 \% se concentró en el ámbito territorial la Ciudad Autónoma de Buenos Aires.

En la jurisdicción federal se concentró el $51 \%$ de las designaciones, mientras que el $31 \%$ se asignó al ámbito federal del interior y el $14 \%$ a la Justicia Nacional.

\section{Designaciones en cargos del Ministerio Público Fiscal en el país}

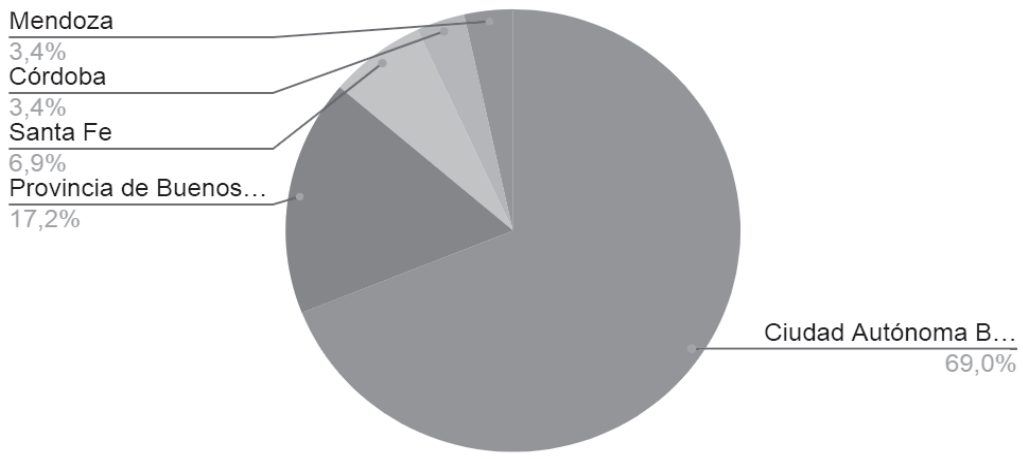

Asimismo, el $38 \%$ de los nombramientos fue para cargos en los organismos de Alzada y otro $38 \%$ fue en cargos del seno de la Procuración General de la Nación. El 24 \% restante se asignó a la primera instancia.

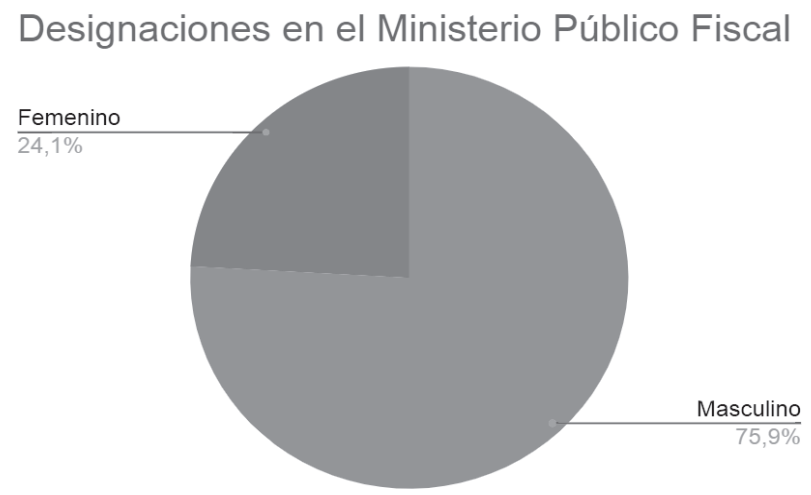


Por otra parte, el $76 \%$ de los nombramientos fueron para hombres y el $24 \%$ para mujeres.

\section{Conclusión general}

La designación de magistrados constituye una atribución que la Constitución Nacional le asigna al Poder Ejecutivo, previa terna del Consejo de la Magistratura para el caso de jueces inferiores a la Corte Suprema, resultante de un concurso público ante dicho órgano ${ }^{8}$.

La importancia de la cobertura de vacantes del sistema de Justicia es un factor central de la institucionalidad de nuestro país ${ }^{9}$, por eso, resulta determinante atender a este proceso.

En tal sentido, en esta nota hemos puesto la mirada cuantitativa sobre los nombramientos efectuados durante la presidencia de MACRI (2015-2019) con criterios de clasificación en órgano, género, grado, geográficos, entre otros aspectos, a los fines de servir en la difusión de la información pública sobre este punto.

\section{Anexo Documental. Designaciones de magistrados desde 10 de diciembre de 2015 hasta 10 de diciembre de 2019}

\begin{tabular}{|l|l|l|c|}
\hline \multicolumn{1}{|c|}{ Nombre } & \multicolumn{1}{c|}{ Organismo } & \multicolumn{1}{|c|}{ Cargo } & Decreto \\
\hline $\begin{array}{l}\text { María Delfina } \\
\text { DENOGENS }\end{array}$ & Poder Judicial & $\begin{array}{l}\text { VOCAL DE LA CAMARA } \\
\text { FEDERAL DE APELACIONES DE } \\
\text { RESISTENCIA }\end{array}$ & $\begin{array}{c}\text { Decreto } \\
285 / 2016\end{array}$ \\
\hline
\end{tabular}

\footnotetext{
8 Se trata del mecanismo previsto en el artículo 99 inciso 4 y 114 de la Constitución Nacional.

9 En ese sentido, resulta de gran interés el detallado trabajo de Juan Rafael Stinco, "Las reformas del sistema de administración de justicia y los procesos de selección de magistrados", publicado en Revista Derecho en Acción (UNLP), Número 12, 2019, el trabajo de Federico G. TheA, "La elección de 'jueces constitucionales'”, publicado en Revista Pensar en Derecho (UBA), Número 4, 2014 y el informe del Laboratorio de Estudios sobre Administración del Poder Judicial de la UNPAZ, “Elección de jueces y juezas. Demoras y (falta de) criterios en las democracias actuales", Número 3, 2019, disponible en línea, por destacar algunas producciones sobre este tema.
} 


\begin{tabular}{|c|c|c|c|}
\hline Nombre & Organismo & Cargo & Decreto \\
\hline $\begin{array}{l}\text { María Cecilia } \\
\text { GILARDI } \\
\text { MADARIAGA }\end{array}$ & Poder Judicial & $\begin{array}{l}\text { JUEZA del JUZGADO } \\
\text { NACIONAL DE } \\
\text { PRIMERA INSTANCIA } \\
\text { EN LO CONTENCIOSO } \\
\text { ADMINISTRATIVO FEDERAL } \\
\text { № } 8 \text { DE LA CAPITAL FEDERAL }\end{array}$ & $\begin{array}{c}\text { Decreto } \\
791 / 2016\end{array}$ \\
\hline $\begin{array}{l}\text { Abel FLEMING } \\
\text { FIGUEROA }\end{array}$ & Poder Judicial & $\begin{array}{l}\text { JUEZ DE CAMARA del } \\
\text { TRIBUNAL ORAL EN LO } \\
\text { CRIMINAL FEDERAL N }{ }^{\circ} 2 \text { DE } \\
\text { SALTA }\end{array}$ & $\begin{array}{c}\text { Decreto } \\
793 / 2016\end{array}$ \\
\hline $\begin{array}{l}\text { Analía Julieta } \\
\text { VIGANO }\end{array}$ & Poder Judicial & $\begin{array}{l}\text { JUEZA del JUZGADO } \\
\text { NACIONAL DE PRIMERA } \\
\text { INSTANCIA DEL TRABAJO Nº } 31 \\
\text { DE LA CAPITAL FEDERAL } \\
\end{array}$ & $\begin{array}{c}\text { Decreto } \\
794 / 2016\end{array}$ \\
\hline $\begin{array}{l}\text { Guillermo } \\
\text { Gustavo LLERAL }\end{array}$ & Poder Judicial & $\begin{array}{l}\text { JUEZ del JUZGADO FEDERAL } \\
\text { DE PRIMERA INSTANCIA N }{ }^{0} 2 \\
\text { DE RAWSON }\end{array}$ & $\begin{array}{c}\text { Decreto } \\
788 / 2016\end{array}$ \\
\hline $\begin{array}{l}\text { Javier Matías } \\
\text { ARZUBI CALVO }\end{array}$ & $\begin{array}{l}\text { Ministerio } \\
\text { Público Fiscal }\end{array}$ & $\begin{array}{l}\text { FISCAL ante el JUZGADO } \\
\text { FEDERAL DE PRIMERA } \\
\text { INSTANCIA DE VENADO } \\
\text { TUERTO }\end{array}$ & $\begin{array}{c}\text { Decreto } \\
789 / 2016\end{array}$ \\
\hline $\begin{array}{l}\text { Santiago } \\
\text { OTTAVIANO }\end{array}$ & $\begin{array}{l}\text { Ministerio } \\
\text { Público de la } \\
\text { Defensa }\end{array}$ & $\begin{array}{l}\text { DEFENSOR PUBLICO OFICIAL } \\
\text { ANTE LOS JUZGADOS } \\
\text { NACIONALES EN LO } \\
\text { CORRECCIONAL Y ANTE LA } \\
\text { CAMARA NACIONAL DE } \\
\text { APELACIONES EN LO CRIMINAL } \\
\text { Y CORRECCIONAL DE LA } \\
\text { CAPITAL FEDERAL, DEFENSORIA } \\
\text { № } 2\end{array}$ & $\begin{array}{c}\text { Decreto } \\
790 / 2016\end{array}$ \\
\hline $\begin{array}{l}\text { Fernando María } \\
\text { KLAPPENBACH }\end{array}$ & $\begin{array}{l}\text { Ministerio } \\
\text { Público Fiscal }\end{array}$ & $\begin{array}{l}\text { FISCAL GENERAL ante los } \\
\text { TRIBUNALES ORALES EN L0 } \\
\text { CRIMINAL DE LA CAPITAL } \\
\text { FEDERAL, FISCALIA N } 14 \\
\end{array}$ & $\begin{array}{c}\text { Decreto } \\
\text { 792/2016 }\end{array}$ \\
\hline $\begin{array}{l}\text { Pablo Nicolás } \\
\text { TURANO }\end{array}$ & $\begin{array}{l}\text { Ministerio } \\
\text { Público Fiscal }\end{array}$ & $\begin{array}{l}\text { FISCAL de la PROCURACION } \\
\text { GENERAL DE LA NACION }\end{array}$ & $\begin{array}{c}\text { Decreto } \\
795 / 2016\end{array}$ \\
\hline
\end{tabular}




\begin{tabular}{|c|c|c|c|}
\hline Nombre & Organismo & Cargo & Decreto \\
\hline $\begin{array}{l}\text { María Luisa } \\
\text { PIQUE }\end{array}$ & $\begin{array}{l}\text { Ministerio } \\
\text { Público Fiscal }\end{array}$ & $\begin{array}{l}\text { FISCAL de la PROCURACION } \\
\text { GENERAL DE LA NACION }\end{array}$ & $\begin{array}{c}\text { Decreto } \\
796 / 2016\end{array}$ \\
\hline $\begin{array}{l}\text { Horacio Daniel } \\
\text { ROSATTI }\end{array}$ & Poder Judicial & $\begin{array}{l}\text { JUEZ de la CORTE SUPREMA DE } \\
\text { JUSTICIA DE LA NACION }\end{array}$ & $\begin{array}{c}\text { Decreto } \\
803 / 2016\end{array}$ \\
\hline $\begin{array}{l}\text { Carlos Fernando } \\
\text { ROSENKRANTZ }\end{array}$ & Poder Judicial & $\begin{array}{l}\text { JUEZ de la CORTE SUPREMA DE } \\
\text { JUSTICIA DE LA NACION }\end{array}$ & $\begin{array}{c}\text { Decreto } \\
804 / 2016\end{array}$ \\
\hline $\begin{array}{l}\text { Domingo José } \\
\text { BATULE }\end{array}$ & Poder Judicial & $\begin{array}{l}\text { JUEZ DE CAMARA del } \\
\text { TRIBUNAL ORAL EN LO } \\
\text { CRIMINAL FEDERAL N } 20 \text { DE } \\
\text { SALTA }\end{array}$ & $\begin{array}{l}\text { Decreto } \\
812 / 2016\end{array}$ \\
\hline $\begin{array}{l}\text { Gabriela Elisa } \\
\text { CATALANO }\end{array}$ & Poder Judicial & $\begin{array}{l}\text { JUEZA DE CAMARA del } \\
\text { TRIBUNAL ORAL EN LO } \\
\text { CRIMINAL FEDERAL Nº } 2 \text { DE } \\
\text { SALTA }\end{array}$ & $\begin{array}{c}\text { Decreto } \\
813 / 2016\end{array}$ \\
\hline $\begin{array}{l}\text { María Alejandra } \\
\text { MANGANO }\end{array}$ & $\begin{array}{l}\text { Ministerio } \\
\text { Público Fiscal }\end{array}$ & $\begin{array}{l}\text { FISCAL de la PROCURACION } \\
\text { GENERAL DE LA NACION }\end{array}$ & $\begin{array}{c}\text { Decreto } \\
811 / 2016\end{array}$ \\
\hline $\begin{array}{l}\text { María Silvina } \\
\text { DOMINGUEZ }\end{array}$ & Poder Judicial & $\begin{array}{l}\text { JUEZA del JUZGADO FEDERAL } \\
\text { DE PRIMERA INSTANCIA DE } \\
\text { ZAPALA }\end{array}$ & $\begin{array}{l}\text { Decreto } \\
815 / 2016\end{array}$ \\
\hline $\begin{array}{l}\text { Juan Carlos } \\
\text { PAULUCCI }\end{array}$ & $\begin{array}{l}\text { Ministerio } \\
\text { Público Fiscal }\end{array}$ & $\begin{array}{l}\text { FISCAL GENERAL ante la } \\
\text { CAMARA FEDERAL DE LA } \\
\text { SEGURIDAD SOCIAL, FISCALIA } \\
N^{0} 2\end{array}$ & $\begin{array}{l}\text { Decreto } \\
814 / 2016\end{array}$ \\
\hline $\begin{array}{l}\text { Andrés Fabián } \\
\text { BASSO }\end{array}$ & Poder Judicial & $\begin{array}{l}\text { Trasládase del TRIBUNAL ORAL } \\
\text { EN LO CRIMINAL FEDERAL } \\
\text { No } 7 \text { DE LA CAPITAL FEDERAL } \\
\text { al TRIBUNAL ORAL EN LO } \\
\text { CRIMINAL FEDERAL N }{ }^{\circ} 3 \text { de la } \\
\text { misma ciudad }\end{array}$ & $\begin{array}{l}\text { Decreto } \\
832 / 2016\end{array}$ \\
\hline $\begin{array}{l}\text { Javier Feliciano } \\
\text { RIOS }\end{array}$ & Poder Judicial & $\begin{array}{l}\text { Trasládase del TRIBUNAL ORAL } \\
\text { EN LO CRIMINAL FEDERAL } \\
\text { No } 7 \text { DE LA CAPITAL FEDERAL } \\
\text { al TRIBUNAL ORAL EN LO } \\
\text { CRIMINAL FEDERAL N }{ }^{0} 3 \text { de la } \\
\text { misma ciudad }\end{array}$ & $\begin{array}{c}\text { Decreto } \\
833 / 2016\end{array}$ \\
\hline
\end{tabular}




\begin{tabular}{|c|c|c|c|}
\hline Nombre & Organismo & Cargo & Decreto \\
\hline $\begin{array}{l}\text { Fernando } \\
\text { Marcelo } \\
\text { MACHADO } \\
\text { PELLONI }\end{array}$ & Poder Judicial & $\begin{array}{l}\text { Trasládase del TRIBUNAL ORAL } \\
\text { EN LO CRIMINAL FEDERAL } \\
\text { Nº } 7 \text { DE LA CAPITAL FEDERAL } \\
\text { al TRIBUNAL ORAL EN LO } \\
\text { CRIMINAL FEDERAL N } 3 \text { de la } \\
\text { misma ciudad }\end{array}$ & $\begin{array}{c}\text { Decreto } \\
900 / 2016\end{array}$ \\
\hline $\begin{array}{l}\text { Juan Ignacio } \\
\text { PEREZ CURCI }\end{array}$ & $\begin{array}{l}\text { Ministerio } \\
\text { Público de la } \\
\text { Defensa }\end{array}$ & $\begin{array}{l}\text { DEFENSOR PUBLICO OFICIAL } \\
\text { ante IOS TRIBUNALES ORALES } \\
\text { EN LO CRIMINAL FEDERAL DE } \\
\text { MENDOZA }\end{array}$ & $\begin{array}{c}\text { Decreto } \\
979 / 2016\end{array}$ \\
\hline $\begin{array}{l}\text { Carolina Laura } \\
\text { Inés ROBIGLIO }\end{array}$ & Poder Judicial & $\begin{array}{l}\text { VOCAL DE LA CAMARA } \\
\text { NACIONAL DE APELACIONES } \\
\text { EN LO PENAL ECONOMICO, } \\
\text { SALA B }\end{array}$ & $\begin{array}{c}\text { Decreto } \\
986 / 2016\end{array}$ \\
\hline $\begin{array}{l}\text { Ana Helena } \\
\text { DIAZ CANO }\end{array}$ & $\begin{array}{l}\text { Ministerio } \\
\text { Público Fiscal }\end{array}$ & $\begin{array}{l}\text { FISCAL GENERAL ANTE LOS } \\
\text { TRIBUNALES ORALES EN LO } \\
\text { CRIMINAL DE LA CAPITAL } \\
\text { FEDERAL, FISCALIA N }{ }^{\circ} 15\end{array}$ & $\begin{array}{c}\text { Decreto } \\
987 / 2016\end{array}$ \\
\hline $\begin{array}{l}\text { José Miguel } \\
\text { IPOHORSKI } \\
\text { LENKIEWICZ } \\
\end{array}$ & $\begin{array}{l}\text { Ministerio } \\
\text { Público Fiscal }\end{array}$ & $\begin{array}{l}\text { FISCAL DE INVESTIGACIONES } \\
\text { ADMINISTRATIVAS }\end{array}$ & $\begin{array}{c}\text { Decreto } \\
988 / 2016\end{array}$ \\
\hline $\begin{array}{l}\text { María Andrea } \\
\text { GARMENDIA } \\
\text { ORUETA } \\
\end{array}$ & $\begin{array}{l}\text { Ministerio } \\
\text { Público Fiscal }\end{array}$ & $\begin{array}{l}\text { FISCAL DE INVESTIGACIONES } \\
\text { ADMINISTRATIVAS }\end{array}$ & $\begin{array}{c}\text { Decreto } \\
985 / 2016\end{array}$ \\
\hline $\begin{array}{l}\text { Sergio Aníbal } \\
\text { PINTO }\end{array}$ & Poder Judicial & $\begin{array}{l}\text { JUEZ del JUZGADO FEDERAL } \\
\text { DE PRIMERA INSTANCIA DE } \\
\text { BELL VILLE, PROVINCIA DE } \\
\text { CÓRDOBA }\end{array}$ & $\begin{array}{c}\text { Decreto } \\
994 / 2016\end{array}$ \\
\hline $\begin{array}{l}\text { Néstor Pablo } \\
\text { BARRAL }\end{array}$ & Poder Judicial & $\begin{array}{l}\text { JUEZ DEL JUZGADO FEDERAL } \\
\text { DE PRIMERA INSTANCIA EN LO } \\
\text { CRIMINAL Y CORRECCIONAL } \\
N^{0} 3 \text { DE MORON, PROVINCIA DE } \\
\text { BUENOS AIRES } \\
\end{array}$ & $\begin{array}{c}\text { Decreto } \\
1062 / 2016\end{array}$ \\
\hline Marcos MORAN & Poder Judicial & $\begin{array}{l}\text { VOCAL DE LA CAMARA } \\
\text { FEDERAL DE APELACIONES DE } \\
\text { SAN MARTIN }\end{array}$ & $\begin{array}{c}\text { Decreto } \\
1072 / 2016\end{array}$ \\
\hline
\end{tabular}




\begin{tabular}{|c|c|c|c|}
\hline Nombre & Organismo & Cargo & Decreto \\
\hline $\begin{array}{l}\text { Hugo Horacio } \\
\text { GRECA }\end{array}$ & Poder Judicial & $\begin{array}{l}\text { JUEZ DEL JUZGADO FEDERAL } \\
\text { DE PRIMERA INSTANCIA DE } \\
\text { GENERAL ROCA }\end{array}$ & $\begin{array}{c}\text { Decreto } \\
1075 / 2016\end{array}$ \\
\hline $\begin{array}{l}\text { Juan Pablo } \\
\text { SALAS }\end{array}$ & Poder Judicial & $\begin{array}{l}\text { VOCAL DE LA CAMARA } \\
\text { FEDERAL DE APELACIONES DE } \\
\text { SAN MARTIN }\end{array}$ & $\begin{array}{c}\text { Decreto } \\
\text { 1076/2016 }\end{array}$ \\
\hline $\begin{array}{l}\text { Walter Ezequiel } \\
\text { LOPEZ DA SILVA }\end{array}$ & Poder Judicial & $\begin{array}{l}\text { JUEZ DEL JUZGADO FEDERAL } \\
\text { DE PRIMERA INSTANCIA N }{ }^{\circ} 1 \\
\text { DE BAHIA BLANCA }\end{array}$ & $\begin{array}{c}\text { Decreto } \\
1077 / 2016\end{array}$ \\
\hline $\begin{array}{l}\text { Carlos Alberto } \\
\text { SEIJAS }\end{array}$ & $\begin{array}{l}\text { Ministerio } \\
\text { Público de la } \\
\text { Defensa }\end{array}$ & $\begin{array}{l}\text { DEFENSOR PUBLICO OFICIAL } \\
\text { ANTE LOS JUZGADOS } \\
\text { NACIONALES EN LO CRIMINAL } \\
\text { DE INSTRUCCION Y ANTE } \\
\text { LA CAMARA NACIONAL DE } \\
\text { APELACIONES EN LO CRIMINAL } \\
\text { Y CORRECCIONAL DE LA } \\
\text { CAPITAL FEDERAL, DEFENSORIA } \\
\text { No } 15\end{array}$ & $\begin{array}{c}\text { Decreto } \\
1074 / 2016\end{array}$ \\
\hline Nicolás LAINO & $\begin{array}{l}\text { Ministerio } \\
\text { Público de la } \\
\text { Defensa }\end{array}$ & $\begin{array}{l}\text { DEFENSOR AUXILIAR DE LA } \\
\text { DEFENSORIA GENERAL DE LA } \\
\text { NACION }\end{array}$ & $\begin{array}{c}\text { Decreto } \\
1081 / 2016\end{array}$ \\
\hline $\begin{array}{l}\text { Martín } \\
\text { Alejandro } \\
\text { RAMOS }\end{array}$ & Poder Judicial & $\begin{array}{l}\text { JUEZ DEL JUZGADO FEDERAL } \\
\text { DE PRIMERA INSTANCIA EN LO } \\
\text { CRIMINAL Y CORRECCIONAL } \\
\text { No } 1 \text { DE MORON }\end{array}$ & $\begin{array}{c}\text { Decreto } \\
1202 / 2016\end{array}$ \\
\hline $\begin{array}{l}\text { Eduardo Ariel } \\
\text { PUIGDENGOLAS }\end{array}$ & Poder Judicial & $\begin{array}{l}\text { JUZGADO FEDERAL DE } \\
\text { PRIMERA INSTANCIA DE SAN } \\
\text { RAFAEL }\end{array}$ & $\begin{array}{c}\text { Decreto } \\
1223 / 2016\end{array}$ \\
\hline $\begin{array}{l}\text { Aurelio Antonio } \\
\text { CUELLO MURUA }\end{array}$ & Poder Judicial & $\begin{array}{l}\text { JUZGADO FEDERAL DE } \\
\text { PRIMERA INSTANCIA DE } \\
\text { VENADO TUERTO }\end{array}$ & $\begin{array}{c}\text { Decreto } \\
1224 / 2016\end{array}$ \\
\hline $\begin{array}{l}\text { Graciela Alicia } \\
\text { GILS CARBO }\end{array}$ & $\begin{array}{l}\text { Ministerio } \\
\text { Público Fiscal }\end{array}$ & $\begin{array}{l}\text { FISCAL GENERAL ANTE LOS } \\
\text { TRIBUNALES ORALES EN LO } \\
\text { CRIMINAL DE LA CAPITAL } \\
\text { FEDERAL, FISCALIA N }{ }^{\circ} 26\end{array}$ & $\begin{array}{c}\text { Decreto } \\
1224 / 2016\end{array}$ \\
\hline
\end{tabular}




\begin{tabular}{|c|c|c|c|}
\hline Nombre & Organismo & Cargo & Decreto \\
\hline $\begin{array}{l}\text { FERNANDO } \\
\text { BAZANO }\end{array}$ & $\begin{array}{l}\text { Ministerio } \\
\text { Público de la } \\
\text { Defensa }\end{array}$ & $\begin{array}{l}\text { DEFENSOR PUBLICO OFICIAL } \\
\text { ANTE LOS JUZGADOS FED. DE } \\
\text { PRIMERA INST. EN LO CRIMINAL } \\
\text { Y CORRECC. DE SAN ISIDRO }\end{array}$ & $\begin{array}{c}\text { Decreto } \\
1274 / 2016\end{array}$ \\
\hline $\begin{array}{l}\text { Esteban Eduardo } \\
\text { HANSEN }\end{array}$ & Poder Judicial & $\begin{array}{l}\text { JUZGADO FEDERAL DE PRIMERA } \\
\text { INSTANCIA DE LIBERTADOR } \\
\text { GENERAL SAN MARTIN }\end{array}$ & $\begin{array}{c}\text { Decreto } \\
1303 / 2016\end{array}$ \\
\hline $\begin{array}{l}\text { Carlos Alberto } \\
\text { MARTINEZ } \\
\text { FRUGONI } \\
\end{array}$ & Poder Judicial & $\begin{array}{l}\text { JUZGADO FEDERAL DE } \\
\text { PRIMERA INSTANCIA DE } \\
\text { TARTAGAL }\end{array}$ & $\begin{array}{c}\text { Decreto } \\
1304 / 2016\end{array}$ \\
\hline $\begin{array}{l}\text { Alberto José } \\
\text { MARTINEZ }\end{array}$ & $\begin{array}{l}\text { Ministerio } \\
\text { Público de la } \\
\text { Defensa }\end{array}$ & $\begin{array}{l}\text { DEFENSOR PUBLICO OFICIAL } \\
\text { ANTE LOS TRIBUNALES } \\
\text { FEDERALES DE PRIMERA Y } \\
\text { SEGUNDA INSTANCIA DE } \\
\text { COMODORO RIVADAVIA }\end{array}$ & $\begin{array}{c}\text { Decreto } \\
1305 / 2016\end{array}$ \\
\hline $\begin{array}{l}\text { CARLOS } \\
\text { ALBERTO } \\
\text { MAHIQUES }\end{array}$ & Poder Judicial & $\begin{array}{l}\text { TRASLADASE DE LA CAMARA } \\
\text { NACIONAL DE CASACION EN } \\
\text { LO CRIMINAL Y CORRECCIONAL } \\
\text { DE LA CAPITAL FEDERAL, SALA } \\
\text { III A LA CAMARA FEDERAL } \\
\text { DE CASACION PENAL, SALA II } \\
\text { (VOCALIA VII) }\end{array}$ & $\begin{array}{c}\text { Decreto } \\
328 / 2017\end{array}$ \\
\hline $\begin{array}{l}\text { ZUNILDA } \\
\text { NIREMPERGER }\end{array}$ & Poder Judicial & $\begin{array}{l}\text { TRASLADASE DEL JUZGADO } \\
\text { FEDERAL DE PRIMERA } \\
\text { INSTANCIA N }{ }^{\circ} 2 \text { DE } \\
\text { RESISTENCIA, PROVINCIA DEL } \\
\text { CHACO AL JUZGADO FEDERAL } \\
\text { DE PRIMERA INSTANCIA N }{ }^{0} 1 \\
\text { DE LA MISMA CIUDAD }\end{array}$ & $\begin{array}{c}\text { Decreto } \\
354 / 2017\end{array}$ \\
\hline $\begin{array}{l}\text { GUILLERMO } \\
\text { JORGE } \\
\text { YACOBUCCI }\end{array}$ & Poder Judicial & $\begin{array}{l}\text { TRANSFORMAR - EN LOS } \\
\text { TERMINOS DEL ARTICU- } \\
\text { LO } 2^{\circ} \text { DE LA LEY } 27.307 \\
\text { - EL TRIBUNAL ORAL EN LO } \\
\text { CRIMINAL N } 6 \text { } 6 \text { DE LA CAPITAL } \\
\text { FEDERAL EN EL TRIBUNAL } \\
\text { ORAL EN LO CRIMINAL } \\
\text { FEDERAL N } 7 \text { DE LA CAPITAL } \\
\text { FEDERAL }\end{array}$ & $\begin{array}{l}\text { Resolución } \\
\text { CM } \\
160 / 2017\end{array}$ \\
\hline
\end{tabular}




\begin{tabular}{|c|c|c|c|}
\hline Nombre & Organismo & Cargo & Decreto \\
\hline $\begin{array}{l}\text { ENRIQUE } \\
\text { MENDEZ } \\
\text { SIGNORI }\end{array}$ & Poder Judicial & $\begin{array}{l}\text { TRANSFORMAR - EN LOS } \\
\text { TERMINOS DEL ARTICULO } 2^{\circ} \text { DE } \\
\text { LA LEY } 27.307 \text { - EL TRIBUNAL } \\
\text { ORAL EN LO CRIMINAL N } 6 \\
\text { DE LA CAPITAL FEDERAL EN } \\
\text { EL TRIBUNAL ORAL EN LO } \\
\text { CRIMINAL FEDERAL N } 7 \text { DE LA } \\
\text { CAPITAL FEDERAL }\end{array}$ & $\begin{array}{l}\text { Resolución } \\
\text { CM } \\
\text { 160/2017 }\end{array}$ \\
\hline $\begin{array}{l}\text { HERMINIO } \\
\text { FERNANDO } \\
\text { CANERO }\end{array}$ & Poder Judicial & $\begin{array}{l}\text { TRANSFORMAR - EN LOS } \\
\text { TERMINOS DEL ARTICULO } 2^{\circ} \text { DE } \\
\text { LA LEY } 27.307 \text { - EL TRIBUNAL } \\
\text { ORAL EN LO CRIMINAL N }{ }^{\circ} 6 \\
\text { DE LA CAPITAL FEDERAL EN } \\
\text { EL TRIBUNAL ORAL EN LO } \\
\text { CRIMINAL FEDERAL N } 7 \text { DE LA } \\
\text { CAPITAL FEDERAL }\end{array}$ & $\begin{array}{l}\text { Resolución } \\
\text { CM } \\
\text { 160/2017 }\end{array}$ \\
\hline $\begin{array}{l}\text { Graciela Haydeé } \\
\text { AVALLONE }\end{array}$ & Poder Judicial & $\begin{array}{l}\text { JUEZA DEL JUZGADO } \\
\text { NACIONAL DE PRIMERA } \\
\text { INSTANCIA DEL TRABAJO No } 49 \\
\text { DE LA CAPITAL FEDERAL }\end{array}$ & $\begin{array}{c}\text { Decreto } \\
546 / 2017\end{array}$ \\
\hline $\begin{array}{l}\text { Claudio Fabián } \\
\text { LOGUARRO }\end{array}$ & Poder Judicial & $\begin{array}{l}\text { JUEZ DEL JUZGADO NACIONAL } \\
\text { DE PRIMERA INSTANCIA DEL } \\
\text { TRABAJO Nº } 38 \text { DE LA CAPITAL } \\
\text { FEDERAL }\end{array}$ & $\begin{array}{c}\text { Decreto } \\
545 / 2017\end{array}$ \\
\hline $\begin{array}{l}\text { Mario Jorge } \\
\text { GAMBACORTA }\end{array}$ & Poder Judicial & $\begin{array}{l}\text { JUEZ DE CAMARA DEL } \\
\text { TRIBUNAL ORAL EN LO } \\
\text { CRIMINAL FEDERAL N } 3 \text { DE } \\
\text { ROSARIO }\end{array}$ & $\begin{array}{c}\text { Decreto } \\
548 / 2017\end{array}$ \\
\hline Marcelo GOTA & Poder Judicial & $\begin{array}{l}\text { JUEZ DEL JUZGADO NACIONAL } \\
\text { DE PRIMERA INSTANCIA EN LO } \\
\text { CIVIL Y COMERCIAL FEDERAL } \\
\text { No } 8 \text { DE LA CAPITAL FEDERAL }\end{array}$ & $\begin{array}{c}\text { Decreto } \\
547 / 2017\end{array}$ \\
\hline $\begin{array}{l}\text { Eduardo Daniel } \\
\text { GOTTARDI }\end{array}$ & Poder Judicial & $\begin{array}{l}\text { VOCAL DE LA CAMARA } \\
\text { NACIONAL DE APELACIONES } \\
\text { EN LO CIVIL Y COMERCIAL } \\
\text { FEDERAL DE LA CAPITAL } \\
\text { FEDERAL, SALA II }\end{array}$ & $\begin{array}{c}\text { Decreto } \\
550 / 2017\end{array}$ \\
\hline
\end{tabular}




\begin{tabular}{|c|c|c|c|}
\hline Nombre & Organismo & Cargo & Decreto \\
\hline $\begin{array}{l}\text { Silvia Susana } \\
\text { SANTOS }\end{array}$ & Poder Judicial & $\begin{array}{l}\text { JUEZA DEL JUZGADO } \\
\text { NACIONAL DE PRIMERA } \\
\text { INSTANCIA DEL TRABAJO No } 68 \\
\text { DE LA CAPITAL FEDERAL } \\
\end{array}$ & $\begin{array}{c}\text { Decreto } \\
549 / 2017\end{array}$ \\
\hline $\begin{array}{l}\text { Germán Luis } \\
\text { Antonio SUTTER } \\
\text { SCHNEIDER }\end{array}$ & Poder Judicial & $\begin{array}{l}\text { JUEZ DE CAMARA DEL } \\
\text { TRIBUNAL ORAL EN LO } \\
\text { CRIMINAL FEDERAL Nº } 1 \text { DE } \\
\text { ROSARIO }\end{array}$ & $\begin{array}{c}\text { Decreto } \\
555 / 2017\end{array}$ \\
\hline $\begin{array}{l}\text { Silvina Andrea } \\
\text { BRACAMONTE }\end{array}$ & Poder Judicial & $\begin{array}{l}\text { JUEZA DEL JUZGADO } \\
\text { NACIONAL DE PRIMERA } \\
\text { INSTANCIA EN LO CIVIL Y } \\
\text { COMERCIAL FEDERAL N }{ }^{0} 1 \text { DE } \\
\text { LA CAPITAL FEDERAL }\end{array}$ & $\begin{array}{c}\text { Decreto } \\
556 / 2017\end{array}$ \\
\hline $\begin{array}{l}\text { María Paula } \\
\text { MARISI }\end{array}$ & Poder Judicial & $\begin{array}{l}\text { JUEZA DE CAMARA DEL } \\
\text { TRIBUNAL ORAL EN LO } \\
\text { CRIMINAL FEDERAL N } 1 \text { DE } \\
\text { MENDOZA }\end{array}$ & $\begin{array}{c}\text { Decreto } \\
557 / 2017\end{array}$ \\
\hline $\begin{array}{l}\text { Santiago José } \\
\text { MARTIN }\end{array}$ & Poder Judicial & $\begin{array}{l}\text { JUEZ DEL JUZGADO FEDERAL } \\
\text { DE PRIMERA INSTANCIA N }{ }^{\circ} 2 \\
\text { DE MAR DEL PLATA }\end{array}$ & $\begin{array}{c}\text { Decreto } \\
558 / 2017\end{array}$ \\
\hline $\begin{array}{l}\text { Javier PICO } \\
\text { TERRERO }\end{array}$ & Poder Judicial & $\begin{array}{l}\text { JUEZ DEL JUZGADO NACIONAL } \\
\text { DE PRIMERA INSTANCIA EN LO } \\
\text { CIVIL Y COMERCIAL FEDERAL } \\
\text { № } 7 \text { DE LA CAPITAL FEDERAL }\end{array}$ & $\begin{array}{c}\text { Decreto } \\
559 / 2017\end{array}$ \\
\hline $\begin{array}{l}\text { Eugenio Jorge } \\
\text { MARTINEZ } \\
\text { FERRERO }\end{array}$ & Poder Judicial & $\begin{array}{l}\text { JUEZ DE CAMARA DEL } \\
\text { TRIBUNAL ORAL EN LO } \\
\text { CRIMINAL FEDERAL N } 3 \text { DE } \\
\text { ROSARIO }\end{array}$ & $\begin{array}{c}\text { Decreto } \\
563 / 2017\end{array}$ \\
\hline $\begin{array}{l}\text { Alberto Daniel } \\
\text { CARELLI }\end{array}$ & Poder Judicial & $\begin{array}{l}\text { JUEZ DE CAMARA DEL } \\
\text { TRIBUNAL ORAL EN LO } \\
\text { CRIMINAL FEDERAL N } 1 \text { DE } \\
\text { MENDOZA }\end{array}$ & $\begin{array}{c}\text { Decreto } \\
567 / 2017\end{array}$ \\
\hline $\begin{array}{l}\text { María Elena } \\
\text { LOPEZ }\end{array}$ & Poder Judicial & $\begin{array}{l}\text { JUEZA DEL JUZGADO } \\
\text { NACIONAL DE PRIMERA } \\
\text { INSTANCIA DEL TRABAJO N } 57 \\
\text { DE LA CAPITAL FEDERAL }\end{array}$ & $\begin{array}{c}\text { Decreto } \\
565 / 2017\end{array}$ \\
\hline
\end{tabular}




\begin{tabular}{|c|c|c|c|}
\hline Nombre & Organismo & Cargo & Decreto \\
\hline $\begin{array}{l}\text { Osvaldo Alberto } \\
\text { FACCIANO }\end{array}$ & Poder Judicial & $\begin{array}{l}\text { JUEZ DE CAMARA DEL } \\
\text { TRIBUNAL ORAL EN LO } \\
\text { CRIMINAL FEDERAL N } 3 \text { DE } \\
\text { ROSARIO }\end{array}$ & $\begin{array}{c}\text { Decreto } \\
566 / 2017\end{array}$ \\
\hline $\begin{array}{l}\text { Jorge Gustavo } \\
\text { ONEL }\end{array}$ & $\begin{array}{l}\text { Ministerio } \\
\text { Público Fiscal }\end{array}$ & $\begin{array}{l}\text { FISCAL ANTE LOS JUZGADOS } \\
\text { FEDERALES DE PRIMERA } \\
\text { INSTANCIA DE SANTA FE, } \\
\text { PROVINCIA DE SANTA FE, } \\
\text { FISCALIA N }{ }^{0} 1\end{array}$ & $\begin{array}{c}\text { Decreto } \\
564 / 2017\end{array}$ \\
\hline $\begin{array}{l}\text { José Carlos } \\
\text { BENITEZ }\end{array}$ & $\begin{array}{l}\text { Ministerio } \\
\text { Público de la } \\
\text { Defensa }\end{array}$ & $\begin{array}{l}\text { DEFENSOR PUBLICO OFICIAL } \\
\text { ANTE EL JUZGADO FEDERAL } \\
\text { DE PRIMERA INSTANCIA DE } \\
\text { PUERTO IGUAZU }\end{array}$ & $\begin{array}{c}\text { Decreto } \\
561 / 2017\end{array}$ \\
\hline \begin{tabular}{|l|} 
David Andrés \\
CHASSAGNADE
\end{tabular} & $\begin{array}{l}\text { Ministerio } \\
\text { Público de la } \\
\text { Defensa }\end{array}$ & $\begin{array}{l}\text { DEFENSOR PUBLICO OFICIAL } \\
\text { ANTE LOS JUZGADOS } \\
\text { FEDERALES DE PRIMERA } \\
\text { INSTANCIA DE RAWSON }\end{array}$ & $\begin{array}{c}\text { Decreto } \\
562 / 2017\end{array}$ \\
\hline $\begin{array}{l}\text { Silvina Andrea } \\
\text { COSTA }\end{array}$ & $\begin{array}{l}\text { Ministerio } \\
\text { Público de la } \\
\text { Defensa }\end{array}$ & $\begin{array}{l}\text { DEFENSORA PUBLICA OFICIAL } \\
\text { ANTE EL JUZGADO FEDERAL } \\
\text { DE PRIMERA INSTANCIA DE } \\
\text { VENADO TUERTO }\end{array}$ & $\begin{array}{c}\text { Decreto } \\
560 / 2017\end{array}$ \\
\hline \begin{tabular}{|l|} 
Guillermo \\
Miguel GARONE
\end{tabular} & $\begin{array}{l}\text { Ministerio } \\
\text { Público de la } \\
\text { Defensa }\end{array}$ & $\begin{array}{l}\text { DEFENSOR PUBLICO OFICIAL } \\
\text { ANTE EL JUZGADO FEDERAL DE } \\
\text { PRIMERA INSTANCIA DE RIO } \\
\text { GRANDE }\end{array}$ & $\begin{array}{c}\text { Decreto } \\
552 / 2017\end{array}$ \\
\hline $\begin{array}{l}\text { José Gabriel } \\
\text { BONGIOVANNI } \\
\text { SERVERA }\end{array}$ & $\begin{array}{l}\text { Ministerio } \\
\text { Público de la } \\
\text { Defensa }\end{array}$ & $\begin{array}{l}\text { DEFENSOR PUBLICO OFICIAL } \\
\text { ANTE EL JUZGADO FEDERAL } \\
\text { DE PRIMERA INSTANCIA DE } \\
\text { USHUAIA }\end{array}$ & $\begin{array}{l}\text { Decreto } \\
551 / 2017\end{array}$ \\
\hline $\begin{array}{l}\text { Lara Cristina } \\
\text { LEGUIZAMON }\end{array}$ & $\begin{array}{l}\text { Ministerio } \\
\text { Público de la } \\
\text { Defensa }\end{array}$ & $\begin{array}{l}\text { DEFENSORA PUBLICA OFICIAL } \\
\text { ANTE LOS JUZGADOS } \\
\text { FEDERALES DE PRIMERA } \\
\text { INSTANCIA DE CORRIENTES }\end{array}$ & $\begin{array}{c}\text { Decreto } \\
554 / 2017\end{array}$ \\
\hline $\begin{array}{l}\text { Rosana Leonor } \\
\text { MARINI }\end{array}$ & $\begin{array}{l}\text { Ministerio } \\
\text { Público de la } \\
\text { Defensa }\end{array}$ & $\begin{array}{l}\text { DEFENSORA PUBLICA OFICIAL } \\
\text { ANTE EL JUZGADO FEDERAL DE } \\
\text { PRIMERA INSTANCIA DE GOYA }\end{array}$ & $\begin{array}{c}\text { Decreto } \\
553 / 2017\end{array}$ \\
\hline
\end{tabular}




\begin{tabular}{|c|c|c|c|}
\hline Nombre & Organismo & Cargo & Decreto \\
\hline $\begin{array}{l}\text { Nicolás } \\
\text { RAMAYON }\end{array}$ & $\begin{array}{l}\text { Ministerio } \\
\text { Público de la } \\
\text { Defensa }\end{array}$ & $\begin{array}{l}\text { DEFENSOR PUBLICO OFICIAL } \\
\text { ANTE EL JUZGADO FEDERAL } \\
\text { DE PRIMERA INSTANCIA DE } \\
\text { RECONOUISTA }\end{array}$ & $\begin{array}{l}\text { Decreto } \\
568 / 2017\end{array}$ \\
\hline $\begin{array}{l}\text { Pablo Juan } \\
\text { LEGA }\end{array}$ & $\begin{array}{l}\text { Ministerio } \\
\text { Público de la } \\
\text { Defensa }\end{array}$ & $\begin{array}{l}\text { DEFENSOR PUBLICO OFICIAL } \\
\text { ANTE EL JUZGADO FEDERAL } \\
\text { DE PRIMERA INSTANCIA DE } \\
\text { PEHUAJO }\end{array}$ & $\begin{array}{c}\text { Decreto } \\
576 / 2017\end{array}$ \\
\hline $\begin{array}{l}\text { Victoria } \\
\text { SANCHEZ } \\
\text { SOULIE }\end{array}$ & $\begin{array}{l}\text { Ministerio } \\
\text { Público de la } \\
\text { Defensa }\end{array}$ & $\begin{array}{l}\text { DEFENSORA PUBLICA OFICIAL } \\
\text { ANTE LOS JUZGADOS } \\
\text { FEDERALES DE PRIMERA } \\
\text { INSTANCIA DE AZUL }\end{array}$ & $\begin{array}{c}\text { Decreto } \\
583 / 2017\end{array}$ \\
\hline Carlos POSE & Poder Judicial & $\begin{array}{l}\text { VOCAL DE LA CAMARA } \\
\text { NACIONAL DE APELACIONES } \\
\text { DEL TRABAJO DE LA CAPITAL } \\
\text { FEDERAL }\end{array}$ & $\begin{array}{c}\text { Decreto } \\
752 / 2017\end{array}$ \\
\hline $\begin{array}{l}\text { María Cecilia } \\
\text { HOCKL }\end{array}$ & Poder Judicial & $\begin{array}{l}\text { VOCAL DE LA CAMARA } \\
\text { NACIONAL DE APELACIONES } \\
\text { DEL TRABAJO DE LA CAPITAL } \\
\text { FEDERAL }\end{array}$ & $\begin{array}{c}\text { Decreto } \\
753 / 2017\end{array}$ \\
\hline $\begin{array}{l}\text { Fernando } \\
\text { Alcides URIARTE }\end{array}$ & Poder Judicial & $\begin{array}{l}\text { VOCAL DE LA CAMARA } \\
\text { NACIONAL DE APELACIONES EN } \\
\text { LO CIVIL Y COMERCIAL FEDERAL } \\
\text { DE LA CAPITAL FEDERAL }\end{array}$ & $\begin{array}{c}\text { Decreto } \\
750 / 2017\end{array}$ \\
\hline $\begin{array}{l}\text { Olga Pura } \\
\text { ARRABAL }\end{array}$ & Poder Judicial & $\begin{array}{l}\text { VOCAL DE LA CAMARA FEDERAL } \\
\text { DE APELACIONES DE MENDOZA }\end{array}$ & $\begin{array}{c}\text { Decreto } \\
751 / 2017\end{array}$ \\
\hline $\begin{array}{l}\text { Alfredo Rafael } \\
\text { PORRAS }\end{array}$ & Poder Judicial & $\begin{array}{l}\text { VOCAL DE LA CAMARA FEDERAL } \\
\text { DE APELACIONES DE MENDOZA }\end{array}$ & $\begin{array}{c}\text { Decreto } \\
756 / 2017\end{array}$ \\
\hline $\begin{array}{l}\text { Alejandro Hugo } \\
\text { PERUGINI }\end{array}$ & Poder Judicial & $\begin{array}{l}\text { VOCAL DE LA CAMARA } \\
\text { NACIONAL DE APELACIONES } \\
\text { DEL TRABAJO DE LA CAPITAL } \\
\text { FEDERAL }\end{array}$ & $\begin{array}{c}\text { Decreto } \\
754 / 2017\end{array}$ \\
\hline $\begin{array}{l}\text { Mauricio Gabriel } \\
\text { ZAMBIAZZO }\end{array}$ & $\begin{array}{l}\text { Ministerio } \\
\text { Público de la } \\
\text { Defensa }\end{array}$ & $\begin{array}{l}\text { DEFENSOR PUBLICO OFICIAL } \\
\text { ANTE EL JUZGADO FEDERAL } \\
\text { DE PRIMERA INSTANCIA DE } \\
\text { CONCORDIA }\end{array}$ & $\begin{array}{c}\text { Decreto } \\
757 / 2017\end{array}$ \\
\hline
\end{tabular}




\begin{tabular}{|c|c|c|c|}
\hline Nombre & Organismo & Cargo & Decreto \\
\hline $\begin{array}{l}\text { Carlos María } \\
\text { CASAS } \\
\text { NOBLEGA }\end{array}$ & $\begin{array}{l}\text { Ministerio } \\
\text { Público Fiscal }\end{array}$ & $\begin{array}{l}\text { FISCAL GENERAL ANTE LOS } \\
\text { TRIBUNALES ORALES EN } \\
\text { LO CRIMINAL FEDERAL DE } \\
\text { CORDOBA }\end{array}$ & $\begin{array}{r}\text { Decreto } \\
755 / 2017\end{array}$ \\
\hline $\begin{array}{l}\text { María Luz } \\
\text { CASTANY }\end{array}$ & $\begin{array}{l}\text { Ministerio } \\
\text { Público Fiscal }\end{array}$ & $\begin{array}{l}\text { FISCAL DE LA PROCURACION } \\
\text { GENERAL DE LA NACION }\end{array}$ & $\begin{array}{r}\text { Decreto } \\
758 / 2017\end{array}$ \\
\hline $\begin{array}{l}\text { Gustavo Enrique } \\
\text { CASTIÑNEIRA DE } \\
\text { DIOS } \\
\end{array}$ & Poder Judicial & $\begin{array}{l}\text { VOCAL DE LA CAMARA } \\
\text { FEDERAL DE APELACIONES DE } \\
\text { MENDOZA }\end{array}$ & $\begin{array}{r}\text { Decreto } \\
765 / 2017\end{array}$ \\
\hline $\begin{array}{l}\text { José Luis } \\
\text { CASSINERIO }\end{array}$ & Poder Judicial & $\begin{array}{l}\text { JUEZ DEL JUZGADO NACIONAL } \\
\text { DE PRIMERA INSTANCIA EN LO } \\
\text { CIVIL Y COMERCIAL FEDERAL } \\
\text { NN }^{0} \text { DE LA CAPITAL FEDERAL }\end{array}$ & $\begin{array}{r}\text { Decreto } \\
764 / 2017\end{array}$ \\
\hline $\begin{array}{l}\text { Manuel Alberto } \\
\text { PIZARRO }\end{array}$ & Poder Judicial & $\begin{array}{l}\text { VOCAL DE LA CAMARA } \\
\text { FEDERAL DE APELACIONES DE } \\
\text { MENDOZA }\end{array}$ & $\begin{array}{r}\text { Decreto } \\
763 / 2017\end{array}$ \\
\hline $\begin{array}{l}\text { Alejandro } \\
\text { Patricio } \\
\text { MARANIELLO }\end{array}$ & Poder Judicial & $\begin{array}{l}\text { JUEZ DEL JUZGADO NACIONAL } \\
\text { DE PRIMERA INSTANCIA EN LO } \\
\text { CIVIL Y COMERCIAL FEDERAL } \\
\text { No } 5 \text { DE LA CAPITAL FEDERAL }\end{array}$ & $\begin{array}{r}\text { Decreto } \\
761 / 2017\end{array}$ \\
\hline $\begin{array}{l}\text { Juan Ignacio } \\
\text { PEREZ CURCI }\end{array}$ & Poder Judicial & $\begin{array}{l}\text { VOCAL DE LA CAMARA } \\
\text { FEDERAL DE APELACIONES DE } \\
\text { MENDOZA }\end{array}$ & $\begin{array}{r}\text { Decreto } \\
762 / 2017\end{array}$ \\
\hline $\begin{array}{l}\text { María Elvira } \\
\text { ROSON }\end{array}$ & Poder Judicial & \begin{tabular}{|l|} 
JUEZA DEL JUZGADO \\
NACIONAL DE PRIMERA \\
INSTANCIA DEL TRABAJO No 46 \\
DE LA CAPITAL FEDERAL
\end{tabular} & $\begin{array}{r}\text { Decreto } \\
768 / 2017\end{array}$ \\
\hline $\begin{array}{l}\text { Fernando } \\
\text { Ignacio FISZER }\end{array}$ & $\begin{array}{l}\text { Ministerio } \\
\text { Público Fiscal }\end{array}$ & \begin{tabular}{|l|} 
FISCAL GENERAL ANTE LOS \\
TRIBUNALES ORALES EN LO \\
CRIMINAL Y CORRECCIONAL DE \\
LA CAPITAL FEDERAL, FISCALIA \\
$N^{0} 3$
\end{tabular} & $\begin{array}{r}\text { Decreto } \\
770 / 2017\end{array}$ \\
\hline $\begin{array}{l}\text { Juan Manuel } \\
\text { FERNANDEZ } \\
\text { BUZZI }\end{array}$ & $\begin{array}{l}\text { Ministerio } \\
\text { Público Fiscal }\end{array}$ & $\begin{array}{l}\text { FISCAL GENERAL ANTE LOS } \\
\text { TRIBUNALES ORALES EN LO } \\
\text { CRIMINAL Y CORRECCIONAL DE } \\
\text { LA CAPITAL FEDERAL, FISCALIA } \\
N^{0} 5\end{array}$ & $\begin{array}{r}\text { Decreto } \\
769 / 2017\end{array}$ \\
\hline
\end{tabular}




\begin{tabular}{|c|c|c|c|}
\hline Nombre & Organismo & Cargo & Decreto \\
\hline $\begin{array}{l}\text { Gabriel } \\
\text { GONZALEZ DA } \\
\text { SILVA } \\
\end{array}$ & $\begin{array}{l}\text { Ministerio } \\
\text { Público Fiscal }\end{array}$ & $\begin{array}{l}\text { FISCAL GENERAL ADJUNTO DE } \\
\text { LA PROCURACION GENERAL DE } \\
\text { LA NACION }\end{array}$ & $\begin{array}{c}\text { Decreto } \\
771 / 2017\end{array}$ \\
\hline $\begin{array}{l}\text { Enrique María } \\
\text { COMELLAS }\end{array}$ & $\begin{array}{l}\text { Ministerio } \\
\text { Público de la } \\
\text { Defensa }\end{array}$ & $\begin{array}{l}\text { DEFENSOR PUBLICO OFICIAL } \\
\text { ANTE LA CAMARA FEDERAL } \\
\text { DE CASACION PENAL, } \\
\text { DEFENSORIA N }{ }^{\circ} 1\end{array}$ & $\begin{array}{c}\text { Decreto } \\
772 / 2017\end{array}$ \\
\hline $\begin{array}{l}\text { Nicolás } \\
\text { AMELOTTI }\end{array}$ & $\begin{array}{l}\text { Ministerio } \\
\text { Público Fiscal }\end{array}$ & $\begin{array}{l}\text { FISCAL GENERAL ANTE LOS } \\
\text { TRIBUNALES ORALES EN LO } \\
\text { CRIMINAL Y CORRECCIONAL DE } \\
\text { LA CAPITAL FEDERAL, FISCALIA } \\
N^{0} 11\end{array}$ & $\begin{array}{c}\text { Decreto } \\
766 / 2017\end{array}$ \\
\hline $\begin{array}{l}\text { Sandro Fabio } \\
\text { ABRALDES }\end{array}$ & $\begin{array}{l}\text { Ministerio } \\
\text { Público Fiscal }\end{array}$ & $\begin{array}{l}\text { FISCAL GENERAL ANTE LOS } \\
\text { TRIBUNALES ORALES EN LO } \\
\text { CRIMINAL Y CORRECCIONAL DE } \\
\text { LA CAPITAL FEDERAL, FISCALIA } \\
\text { N }^{0} 29\end{array}$ & $\begin{array}{c}\text { Decreto } \\
767 / 2017\end{array}$ \\
\hline $\begin{array}{l}\text { Martín } \\
\text { Sebastián } \\
\text { PELUSO } \\
\end{array}$ & Poder Judicial & $\begin{array}{l}\text { JUEZ DEL JUZGADO NACIONAL } \\
\text { EN LO CRIMINAL Y CORRECCIONAL } \\
\text { No } 9 \text { DE LA CAPITAL FEDERAL } \\
\end{array}$ & $\begin{array}{c}\text { Decreto } \\
812 / 2017\end{array}$ \\
\hline $\begin{array}{l}\text { Mariano } \\
\text { ITURRALDE }\end{array}$ & Poder Judicial & $\begin{array}{l}\text { JUEZ DEL JUZGADO } \\
\text { NACIONAL EN LO CRIMINAL } \\
\text { Y CORRECCIONAL N } 16 \text { DE LA } \\
\text { CAPITAL FEDERAL } \\
\end{array}$ & $\begin{array}{c}\text { Decreto } \\
815 / 2017\end{array}$ \\
\hline $\begin{array}{l}\text { Julio Leonardo } \\
\text { BAVIO }\end{array}$ & Poder Judicial & $\begin{array}{l}\text { JUEZ DEL JUZGADO FEDERAL } \\
\text { DE PRIMERA INSTANCIA N }{ }^{0} 1 \\
\text { DE SALTA }\end{array}$ & $\begin{array}{c}\text { Decreto } \\
813 / 2017\end{array}$ \\
\hline Aníbal PINEDA & Poder Judicial & $\begin{array}{l}\text { VOCAL DE LA CAMARA } \\
\text { FEDERAL DE APELACIONES DE } \\
\text { ROSARIO }\end{array}$ & $\begin{array}{c}\text { Decreto } \\
816 / 2017\end{array}$ \\
\hline $\begin{array}{l}\text { Juan Manuel } \\
\text { IGLESIAS }\end{array}$ & Poder Judicial & $\begin{array}{l}\text { Trasládase del TRIBUNAL ORAL } \\
\text { EN LO CRIMINAL FEDERAL DE } \\
\text { CONCEPCIÓN DEL URUGUAY, } \\
\text { PROVINCIA DE ENTRE RÍOS al } \\
\text { TRIBUNAL ORAL EN LO CRIMINAL } \\
\text { FEDERAL DE RESISTENCIA, } \\
\text { PROVINCIA DEL CHACO }\end{array}$ & $\begin{array}{c}\text { Decreto } \\
875 / 2017\end{array}$ \\
\hline
\end{tabular}




\begin{tabular}{|c|c|c|c|}
\hline Nombre & Organismo & Cargo & Decreto \\
\hline $\begin{array}{l}\text { Federico } \\
\text { BOTHAMLEY }\end{array}$ & Poder Judicial & $\begin{array}{l}\text { JUEZ DE CÁMARA DEL } \\
\text { TRIBUNAL ORAL EN LO } \\
\text { CRIMINAL FEDERAL DE } \\
\text { SANTIAGO DEL ESTERO }\end{array}$ & $\begin{array}{l}\text { Decreto } \\
907 / 2017\end{array}$ \\
\hline $\begin{array}{l}\text { María Alejandra } \\
\text { PROVÍTOLA }\end{array}$ & Poder Judicial & $\begin{array}{l}\text { JUEZA DEL JUZGADO } \\
\text { NACIONAL EN LO CRIMINAL } \\
\text { Y CORRECCIONAL N } 6 \text { DE LA } \\
\text { CAPITAL FEDERAL }\end{array}$ & $\begin{array}{l}\text { Decreto } \\
906 / 2017\end{array}$ \\
\hline $\begin{array}{l}\text { Beatriz Estela } \\
\text { ARANGUREN }\end{array}$ & Poder Judicial & $\begin{array}{l}\text { VOCAL DE LA CÁMARA FEDERAL } \\
\text { DE APELACIONES DE PARANÁ }\end{array}$ & $\begin{array}{l}\text { Decreto } \\
912 / 2017\end{array}$ \\
\hline $\begin{array}{l}\text { Cecilia } \\
\text { Margarita } \\
\text { MURRAY }\end{array}$ & Poder Judicial & \begin{tabular}{|l|} 
JUEZA DEL JUZGADO \\
NACIONAL DE PRIMERA \\
INSTANCIA DEL TRABAJO N 79 \\
DE LA CAPITAL FEDERAL
\end{tabular} & $\begin{array}{l}\text { Decreto } \\
909 / 2017\end{array}$ \\
\hline María Luz FELIPE & $\begin{array}{l}\text { Ministerio } \\
\text { Público de la } \\
\text { Defensa }\end{array}$ & $\begin{array}{l}\text { DEFENSORA PÚBLICA OFICIAL } \\
\text { ANTE EL JUZGADO FEDERAL DE } \\
\text { PRIMERA INSTANCIA DE VILLA } \\
\text { MARÍA }\end{array}$ & $\begin{array}{c}\text { Decreto } \\
910 / 2017\end{array}$ \\
\hline Pablo REPETTO & $\begin{array}{l}\text { Ministerio } \\
\text { Público de la } \\
\text { Defensa }\end{array}$ & $\begin{array}{l}\text { DEFENSOR PÚBLICO OFICIAL } \\
\text { ANTE LOS JUZGADOS } \\
\text { FEDERALES DE PRIMERA } \\
\text { INSTANCIA DE NEUQUÉN }\end{array}$ & $\begin{array}{c}\text { Decreto } \\
905 / 2017\end{array}$ \\
\hline $\begin{array}{l}\text { Elizabeth } \\
\text { Alejandra } \\
\text { PAISÁN }\end{array}$ & Poder Judicial & $\begin{array}{l}\text { JUEZA DEL JUZGADO } \\
\text { NACIONAL EN LO CRIMINAL } \\
\text { Y CORRECCIONAL No } 12 \text { DE LA } \\
\text { CAPITAL FEDERAL }\end{array}$ & $\begin{array}{c}\text { Decreto } \\
917 / 2017\end{array}$ \\
\hline $\begin{array}{l}\text { Rosalía } \\
\text { ROMERO }\end{array}$ & Poder Judicial & \begin{tabular}{|l|} 
JUEZA DEL JUZGADO \\
NACIONAL DE PRIMERA \\
INSTANCIA DEL TRABAJO No 45 \\
DE LA CAPITAL FEDERAL
\end{tabular} & $\begin{array}{l}\text { Decreto } \\
913 / 2017\end{array}$ \\
\hline $\begin{array}{l}\text { Abelardo Jorge } \\
\text { BASBÚS }\end{array}$ & Poder Judicial & $\begin{array}{l}\text { JUEZ DE CÁMARA DEL TRIBUNAL } \\
\text { ORAL EN LO CRIMINAL FEDERAL } \\
\text { DE SANTIAGO DEL ESTERO }\end{array}$ & $\begin{array}{l}\text { Decreto } \\
924 / 2017\end{array}$ \\
\hline Alfredo GODOY & Poder Judicial & $\begin{array}{l}\text { JUEZ DEL JUZGADO } \\
\text { NACIONAL EN LO CRIMINAL } \\
\text { Y CORRECCIONAL Nº } 24 \text { DE LA } \\
\text { CAPITAL FEDERAL }\end{array}$ & $\begin{array}{l}\text { Decreto } \\
920 / 2017\end{array}$ \\
\hline
\end{tabular}




\begin{tabular}{|c|c|c|c|}
\hline Nombre & Organismo & Cargo & Decreto \\
\hline $\begin{array}{l}\text { Martín } \\
\text { YADAROLA }\end{array}$ & Poder Judicial & $\begin{array}{l}\text { JUEZ DEL JUZGADO } \\
\text { NACIONAL EN LO CRIMINAL } \\
\text { Y CORRECCIONAL N } 4 \text { DE LA } \\
\text { CAPITAL FEDERAL }\end{array}$ & $\begin{array}{c}\text { Decreto } \\
921 / 2017\end{array}$ \\
\hline $\begin{array}{l}\text { Fernando Adrián } \\
\text { SÁNCHEZ }\end{array}$ & $\begin{array}{l}\text { Ministerio } \\
\text { Público de la } \\
\text { Defensa }\end{array}$ & $\begin{array}{l}\text { DEFENSOR PÚBLICO OFICIAL } \\
\text { ANTE LOS JUZGADOS } \\
\text { FEDERALES DE PRIMERA } \\
\text { INSTANCIA DE SANTA FE }\end{array}$ & $\begin{array}{c}\text { Decreto } \\
\text { 919/2017 }\end{array}$ \\
\hline $\begin{array}{l}\text { Juan Carlos } \\
\text { NACUL }\end{array}$ & Poder Judicial & $\begin{array}{l}\text { JUEZ DEL JUZGADO FEDERAL } \\
\text { DE PRIMERA INSTANCIA DE } \\
\text { VILLA MERCEDES }\end{array}$ & $\begin{array}{l}\text { Decreto } \\
938 / 2017\end{array}$ \\
\hline $\begin{array}{l}\text { Miguel Ángel } \\
\text { CONTRERAS }\end{array}$ & Poder Judicial & $\begin{array}{l}\text { JUEZ DEL JUZGADO FEDERAL } \\
\text { DE PRIMERA INSTANCIA No } 1 \\
\text { DE CATAMARCA }\end{array}$ & $\begin{array}{c}\text { Decreto } \\
937 / 2017\end{array}$ \\
\hline $\begin{array}{l}\text { Marcos Andrés } \\
\text { FERNÁNDEZ }\end{array}$ & Poder Judicial & $\begin{array}{l}\text { JUEZ DEL JUZGADO } \\
\text { NACIONAL EN LO CRIMINAL } \\
\text { Y CORRECCIONAL N }{ }^{0} 21 \text { DE LA } \\
\text { CAPITAL FEDERAL }\end{array}$ & $\begin{array}{c}\text { Decreto } \\
953 / 2017\end{array}$ \\
\hline $\begin{array}{l}\text { Darío Osvaldo } \\
\text { BONANNO }\end{array}$ & Poder Judicial & $\begin{array}{l}\text { JUEZ DEL JUZGADO } \\
\text { NACIONAL EN LO CRIMINAL } \\
\text { Y CORRECCIONAL N } 33 \text { DE LA } \\
\text { CAPITAL FEDERAL }\end{array}$ & $\begin{array}{c}\text { Decreto } \\
956 / 2017\end{array}$ \\
\hline Paula PETAZZI & Poder Judicial & $\begin{array}{l}\text { JUEZA DEL JUZGADO } \\
\text { NACIONAL EN LO CRIMINAL } \\
\text { Y CORRECCIONAL N }{ }^{\circ} 11 \text { DE LA } \\
\text { CAPITAL FEDERAL }\end{array}$ & $\begin{array}{c}\text { Decreto } \\
959 / 2017\end{array}$ \\
\hline $\begin{array}{l}\text { Ángeles } \\
\text { Mariana GOMEZ } \\
\text { MAIORANO }\end{array}$ & Poder Judicial & $\begin{array}{l}\text { JUEZA DEL JUZGADO } \\
\text { NACIONAL EN LO CRIMINAL } \\
\text { Y CORRECCIONAL N } 49 \text { DE LA } \\
\text { CAPITAL FEDERAL }\end{array}$ & $\begin{array}{c}\text { Decreto } \\
\text { 976/2017 }\end{array}$ \\
\hline Silvina CASTRO & Poder Judicial & $\begin{array}{l}\text { JUEZA DEL JUZGADO } \\
\text { NACIONAL DE PRIMERA } \\
\text { INSTANCIA DEL TRABAJO N } 74 \\
\text { DE LA CAPITAL FEDERAL }\end{array}$ & $\begin{array}{c}\text { Decreto } \\
973 / 2017\end{array}$ \\
\hline $\begin{array}{l}\text { Omar Aníbal } \\
\text { PERALTA }\end{array}$ & Poder Judicial & $\begin{array}{l}\text { JUEZ DEL JUZGADO } \\
\text { NACIONAL EN LO CRIMINAL } \\
\text { Y CORRECCIONAL N } 7 \text { DE LA } \\
\text { CAPITAL FEDERAL }\end{array}$ & $\begin{array}{c}\text { Decreto } \\
971 / 2017\end{array}$ \\
\hline
\end{tabular}




\begin{tabular}{|c|c|c|c|}
\hline Nombre & Organismo & Cargo & Decreto \\
\hline $\begin{array}{l}\text { Mónica María } \\
\text { Inés PINOTTI }\end{array}$ & Poder Judicial & $\begin{array}{l}\text { JUEZA DEL JUZGADO } \\
\text { NACIONAL DE PRIMERA } \\
\text { INSTANCIA DEL TRABAJO Nº } 39 \\
\text { DE LA CAPITAL FEDERAL }\end{array}$ & $\begin{array}{c}\text { Decreto } \\
\text { 974/2017 }\end{array}$ \\
\hline $\begin{array}{l}\text { Alejandro Héctor } \\
\text { FERRO }\end{array}$ & Poder Judicial & $\begin{array}{l}\text { JUEZ DEL JUZGADO } \\
\text { NACIONAL EN LO CRIMINAL } \\
\text { Y CORRECCIONAL Nº } 36 \text { DE LA } \\
\text { CAPITAL FEDERAL }\end{array}$ & $\begin{array}{c}\text { Decreto } \\
975 / 2017\end{array}$ \\
\hline $\begin{array}{l}\text { Héctor Andrés } \\
\text { HEIM }\end{array}$ & $\begin{array}{l}\text { Ministerio } \\
\text { Público Fiscal }\end{array}$ & $\begin{array}{l}\text { FISCAL GENERAL ADJUNTO DE } \\
\text { LA PROCURACIÓN GENERAL DE } \\
\text { LA NACIÓN }\end{array}$ & $\begin{array}{c}\text { Decreto } \\
972 / 2017\end{array}$ \\
\hline $\begin{array}{l}\text { Laura Graciela } \\
\text { BRUNIARD }\end{array}$ & Poder Judicial & $\begin{array}{l}\text { JUEZA DEL JUZGADO } \\
\text { NACIONAL EN LO CRIMINAL } \\
\text { Y CORRECCIONAL N } 34 \text { DE LA } \\
\text { CAPITAL FEDERAL }\end{array}$ & $\begin{array}{c}\text { Decreto } \\
981 / 2017\end{array}$ \\
\hline $\begin{array}{l}\text { Silvia Estela } \\
\text { MORA }\end{array}$ & Poder Judicial & $\begin{array}{l}\text { Transformar, en los términos de } \\
\text { los artículos } 3^{\circ} \text { y } 4^{\circ} \text { de la Ley } \\
27.307, \text { el Tribunal Oral en lo } \\
\text { Criminal y Correccional N }{ }^{0} 10 \text { de } \\
\text { la Capital Federal, en el Tribunal } \\
\text { Oral en lo Criminal Federal No } 9 \\
\text { de la Capital Federal }\end{array}$ & $\begin{array}{l}\text { Resolución } \\
\text { CM } \\
491 / 2017\end{array}$ \\
\hline $\begin{array}{l}\text { Alejandro } \\
\text { Martín BECERRA }\end{array}$ & Poder Judicial & $\begin{array}{l}\text { Transformar, en los términos de } \\
\text { los artículos } 3^{\circ} \text { y } 4^{\circ} \text { de la Ley } \\
27.307, \text { el Tribunal Oral en lo } \\
\text { Criminal y Correccional N }{ }^{\circ} 10 \text { de } \\
\text { la Capital Federal, en el Tribunal } \\
\text { Oral en lo Criminal Federal N }{ }^{\circ} 9 \\
\text { de la Capital Federal }\end{array}$ & $\begin{array}{c}\text { Resolución } \\
\text { CM } \\
491 / 2017\end{array}$ \\
\hline $\begin{array}{l}\text { Alejandro } \\
\text { NOCETTI } \\
\text { ACHAVAL }\end{array}$ & Poder Judicial & $\begin{array}{l}\text { Transformar, en los términos de } \\
\text { los artículos } 3^{\circ} \text { y } 4^{\circ} \text { de la Ley } \\
27.307, \text { el Tribunal Oral en lo } \\
\text { Criminal y Correccional N }{ }^{0} 10 \text { de } \\
\text { la Capital Federal, en el Tribunal } \\
\text { Oral en lo Criminal Federal No } 9 \\
\text { de la Capital Federal }\end{array}$ & $\begin{array}{l}\text { Resolución } \\
\text { CM } \\
491 / 2017\end{array}$ \\
\hline
\end{tabular}




\begin{tabular}{|c|c|c|c|}
\hline Nombre & Organismo & Cargo & Decreto \\
\hline Gerardo BALOG & $\begin{array}{l}\text { Ministerio } \\
\text { Público de la } \\
\text { Defensa }\end{array}$ & $\begin{array}{l}\text { DEFENSOR PÚBLICO OFICIAL } \\
\text { ANTE EL JUZGADO FEDERAL } \\
\text { DE PRIMERA INSTANCIA DE } \\
\text { GENERAL PICO }\end{array}$ & $\begin{array}{c}\text { Decreto } \\
1023 / 2017\end{array}$ \\
\hline $\begin{array}{l}\text { Ricardo Antonio } \\
\text { TITTO }\end{array}$ & $\begin{array}{l}\text { Ministerio } \\
\text { Público de la } \\
\text { Defensa }\end{array}$ & $\begin{array}{l}\text { DEFENSOR PÚBLICO OFICIAL } \\
\text { ANTE LOS JUZGADOS } \\
\text { NACIONALES EN LO CRIMINAL } \\
\text { Y CORRECCIONAL Y ANTE } \\
\text { LA CÁMARA NACIONAL DE } \\
\text { APELACIONES EN LO CRIMINAL } \\
\text { Y CORRECCIONAL DE LA } \\
\text { CAPITAL FEDERAL, DEFENSORÍA } \\
\text { № } 22\end{array}$ & $\begin{array}{l}\text { Decreto } \\
79 / 2018\end{array}$ \\
\hline $\begin{array}{l}\text { Ricardo BUSTOS } \\
\text { FIERRO }\end{array}$ & Poder Judicial & $\begin{array}{l}\text { JUEZ DEL JUZGADO FEDERAL } \\
\text { DE PRIMERA INSTANCIA N }{ }^{0} 1 \\
\text { DE CÓRDOBA }\end{array}$ & $\begin{array}{l}\text { Decreto } \\
77 / 2018\end{array}$ \\
\hline $\begin{array}{l}\text { Eduardo Antonio } \\
\text { ZANNONI }\end{array}$ & Poder Judicial & $\begin{array}{l}\text { VOCAL DE LA CÁMARA } \\
\text { NACIONAL DE APELACIONES } \\
\text { EN LO CIVIL DE LA CAPITAL } \\
\text { FEDERAL, SALA F }\end{array}$ & $\begin{array}{l}\text { Decreto } \\
78 / 2018\end{array}$ \\
\hline $\begin{array}{l}\text { Germán Pablo } \\
\text { ZENOBI }\end{array}$ & Poder Judicial & $\begin{array}{l}\text { JUEZ DEL JUZGADO FEDERAL } \\
\text { DE PRIMERA INSTANCIA DE LA } \\
\text { SEGURIDAD SOCIAL N } 9 \text { DE LA } \\
\text { CAPITAL FEDERAL, }\end{array}$ & $\begin{array}{c}\text { Decreto } \\
329 / 2018\end{array}$ \\
\hline $\begin{array}{l}\text { Elisa Matilde } \\
\text { DIAZ DE VIVAR }\end{array}$ & Poder Judicial & $\begin{array}{l}\text { VOCAL DE LA CÁMARA } \\
\text { NACIONAL DE APELACIONES } \\
\text { EN LO CIVIL DE LA CAPITAL } \\
\text { FEDERAL, SALA M }\end{array}$ & $\begin{array}{c}\text { Decreto } \\
328 / 2018\end{array}$ \\
\hline $\begin{array}{l}\text { Ricardo Gustavo } \\
\text { RECONDO }\end{array}$ & Poder Judicial & $\begin{array}{l}\text { VOCAL DE LA CÁMARA } \\
\text { NACIONAL DE APELACIONES } \\
\text { EN LO CIVIL Y COMERCIAL } \\
\text { FEDERAL DE LA CAPITAL } \\
\text { FEDERAL, SALA III, }\end{array}$ & $\begin{array}{c}\text { Decreto } \\
332 / 2018\end{array}$ \\
\hline $\begin{array}{l}\text { María Claudia } \\
\text { JUEGUEN }\end{array}$ & Poder Judicial & $\begin{array}{l}\text { JUEZA DEL JUZGADO } \\
\text { NACIONAL DE PRIMERA } \\
\text { INSTANCIA DEL TRABAJO № } 34 \\
\text { DE LA CAPITAL FEDERAL } \\
\end{array}$ & $\begin{array}{c}\text { Decreto } \\
316 / 2018\end{array}$ \\
\hline
\end{tabular}




\begin{tabular}{|c|c|c|c|}
\hline Nombre & Organismo & Cargo & Decreto \\
\hline $\begin{array}{l}\text { Damián Ignacio } \\
\text { KIRSZENBAUM }\end{array}$ & Poder Judicial & $\begin{array}{l}\text { JUEZ DEL JUZGADO } \\
\text { NACIONAL EN LO CRIMINAL } \\
\text { Y CORRECCIONAL N }{ }^{\circ} 26 \text { DE LA } \\
\text { CAPITAL FEDERAL }\end{array}$ & $\begin{array}{c}\text { Decreto } \\
312 / 2018\end{array}$ \\
\hline $\begin{array}{l}\text { Carina Nancy } \\
\text { RODRÍGUEZ }\end{array}$ & Poder Judicial & $\begin{array}{l}\text { JUEZA DEL JUZGADO } \\
\text { NACIONAL EN LO CRIMINAL } \\
\text { Y CORRECCIONAL N }{ }^{\circ} 29 \text { DE LA } \\
\text { CAPITAL FEDERAL }\end{array}$ & $\begin{array}{c}\text { Decreto } \\
318 / 2018\end{array}$ \\
\hline Rocío ALCALÁ & Poder Judicial & $\begin{array}{l}\text { VOCAL DE LA CÁMARA } \\
\text { FEDERAL DE APELACIONES DE } \\
\text { RESISTENCIA, PROVINCIA DEL } \\
\text { CHACO }\end{array}$ & $\begin{array}{c}\text { Decreto } \\
321 / 2018\end{array}$ \\
\hline $\begin{array}{l}\text { Luis Alberto } \\
\text { CATARDO }\end{array}$ & Poder Judicial & $\begin{array}{l}\text { VOCAL DE LA CÁMARA } \\
\text { NACIONAL DE APELACIONES } \\
\text { DEL TRABAJO DE LA CAPITAL } \\
\text { FEDERAL, SALA VIII }\end{array}$ & $\begin{array}{c}\text { Decreto } \\
317 / 2018\end{array}$ \\
\hline $\begin{array}{l}\text { Graciela Liliana } \\
\text { CARAMBIA }\end{array}$ & Poder Judicial & $\begin{array}{l}\text { VOCAL DE LA CÁMARA } \\
\text { NACIONAL DE APELACIONES } \\
\text { DEL TRABAJO DE LA CAPITAL } \\
\text { FEDERAL, SALA VII }\end{array}$ & $\begin{array}{c}\text { Decreto } \\
323 / 2018\end{array}$ \\
\hline $\begin{array}{l}\text { Miguel Omar } \\
\text { PÉREZ }\end{array}$ & Poder Judical & $\begin{array}{l}\text { VOCAL DE LA CÁMARA } \\
\text { NACIONAL DE APELACIONES } \\
\text { DEL TRABAJO DE LA CAPITAL } \\
\text { FEDERAL, SALA III, }\end{array}$ & $\begin{array}{c}\text { Decreto } \\
324 / 2018\end{array}$ \\
\hline $\begin{array}{l}\text { Laura Victoria } \\
\text { UBERTAZZI }\end{array}$ & Poder Judicial & $\begin{array}{l}\text { CONJUEZ DE LA CÁMARA } \\
\text { FEDERAL DE APELACIONES DE } \\
\text { COMODORO RIVADAVIA } \\
\end{array}$ & $\begin{array}{c}\text { Decreto } \\
326 / 2018\end{array}$ \\
\hline $\begin{array}{l}\text { Fernando } \\
\text { BUJÁN }\end{array}$ & $\begin{array}{l}\text { Ministerio } \\
\text { Público de la } \\
\text { Defensa }\end{array}$ & $\begin{array}{l}\text { DEFENSOR PÚBLICO OFICIAL } \\
\text { ANTE LOS JUZGADOS } \\
\text { NACIONALES EN LO CRIMINAL } \\
\text { Y CORRECCIONAL Y ANTE } \\
\text { LA CÁMARA NACIONAL DE } \\
\text { APELACIONES EN LO CRIMINAL } \\
\text { Y CORRECCIONAL DE LA } \\
\text { CAPITAL FEDERAL, DEFENSORÍA } \\
\text { No } 16\end{array}$ & $\begin{array}{c}\text { Decreto } \\
325 / 2018\end{array}$ \\
\hline
\end{tabular}




\begin{tabular}{|c|c|c|c|}
\hline Nombre & Organismo & Cargo & Decreto \\
\hline $\begin{array}{l}\text { Juan Antonio } \\
\text { TOBÍAS }\end{array}$ & $\begin{array}{l}\text { Ministerio } \\
\text { Público de la } \\
\text { Defensa }\end{array}$ & $\begin{array}{l}\text { DEFENSOR PÚBLICO OFICIAL } \\
\text { ADJUNTO ANTE LOS } \\
\text { TRIBUNALES ORALES DE } \\
\text { MENORES DE LA CAPITAL } \\
\text { FEDERAL, DEFENSORÍA N }{ }^{\circ} 3\end{array}$ & $\begin{array}{c}\text { Decreto } \\
322 / 2018\end{array}$ \\
\hline $\begin{array}{l}\text { Hernán } \\
\text { PROCAJLO }\end{array}$ & $\begin{array}{l}\text { Ministerio } \\
\text { Público de la } \\
\text { Defensa }\end{array}$ & $\begin{array}{l}\text { DEFENSOR PÚBLICO OFICIAL } \\
\text { ANTE LOS TRIBUNALES } \\
\text { FEDERALES DE PRIMERA Y } \\
\text { SEGUNDA INSTANCIA DE } \\
\text { ROSARIO, PROVINCIA DE } \\
\text { SANTA FÉ, DEFENSORÍA N }{ }^{\circ} 2\end{array}$ & $\begin{array}{c}\text { Decreto } \\
319 / 2018\end{array}$ \\
\hline $\begin{array}{l}\text { Esteban José } \\
\text { CHERVIN }\end{array}$ & \begin{tabular}{|l} 
Ministerio \\
Público de la \\
Defensa \\
\end{tabular} & $\begin{array}{l}\text { DEFENSOR PÚBLICO OFICIAL ANTE } \\
\text { EL TRIBUNAL ORAL EN LO } \\
\text { CRIMINAL FEDERAL DE SAN JUAN }\end{array}$ & $\begin{array}{c}\text { Decreto } \\
320 / 2018\end{array}$ \\
\hline $\begin{array}{l}\text { Hernán José } \\
\text { SANTO } \\
\text { ORIHUELA }\end{array}$ & $\begin{array}{l}\text { Ministerio } \\
\text { Público de la } \\
\text { Defensa }\end{array}$ & $\begin{array}{l}\text { DEFENSOR PÚBLICO OFICIAL } \\
\text { ANTE LOS JUZGADOS } \\
\text { NACIONALES EN LO CRIMINAL } \\
\text { Y CORRECCIONAL Y ANTE } \\
\text { LA CÁMARA NACIONAL DE } \\
\text { APELACIONES EN LO CRIMINAL } \\
\text { Y CORRECCIONAL DE LA } \\
\text { CAPITAL FEDERAL }\end{array}$ & $\begin{array}{c}\text { Decreto } \\
313 / 2018\end{array}$ \\
\hline $\begin{array}{l}\text { Claudia Soledad } \\
\text { IBAÑNEZ }\end{array}$ & \begin{tabular}{|l} 
Ministerio \\
Público de la \\
Defensa
\end{tabular} & $\begin{array}{l}\text { DEFENSORA PÚBLICA OFICIAL } \\
\text { ANTE EL TRIBUNAL ORAL EN LO } \\
\text { CRIMINAL FEDERAL DE SAN LUIS }\end{array}$ & $\begin{array}{c}\text { Decreto } \\
314 / 2018\end{array}$ \\
\hline Leticia Iris DIEZ & $\begin{array}{l}\text { Ministerio } \\
\text { Público de la } \\
\text { Defensa }\end{array}$ & $\begin{array}{l}\text { DEFENSORA PÚBLICA OFICIAL } \\
\text { ANTE EL JUZGADO FEDERAL DE } \\
\text { PRIMERA INSTANCIA DE RÍO } \\
\text { GALLEGOS }\end{array}$ & $\begin{array}{c}\text { Decreto } \\
315 / 2018\end{array}$ \\
\hline $\begin{array}{l}\text { Lucila Inés } \\
\text { CÓRDOBA }\end{array}$ & Poder Judicial & $\begin{array}{l}\text { JUEZA DEL JUZGADO } \\
\text { NACIONAL DE PRIMERA } \\
\text { INSTANCIA EN LO CIVIL No } 8 \text { DE } \\
\text { LA CAPITAL FEDERAL }\end{array}$ & $\begin{array}{c}\text { Decreto } \\
334 / 2018\end{array}$ \\
\hline $\begin{array}{l}\text { María Dora } \\
\text { GONZÁLEZ }\end{array}$ & Poder Judicial & $\begin{array}{l}\text { VOCAL DE LA CÁMARA } \\
\text { NACIONAL DE APELACIONES } \\
\text { DEL TRABAJO DE LA CAPITAL } \\
\text { FEDERAL, SALA VIII }\end{array}$ & $\begin{array}{c}\text { Decreto } \\
333 / 2018\end{array}$ \\
\hline
\end{tabular}




\begin{tabular}{|c|c|c|c|}
\hline Nombre & Organismo & Cargo & Decreto \\
\hline $\begin{array}{l}\text { Samanta } \\
\text { Claudia } \\
\text { BISCARDI }\end{array}$ & Poder Judicial & $\begin{array}{l}\text { JUEZA DEL JUZGADO } \\
\text { NACIONAL DE PRIMERA } \\
\text { INSTANCIA EN LO CIVIL Nº } 81 \\
\text { DE LA CAPITAL FEDERAL }\end{array}$ & $\begin{array}{c}\text { Decreto } \\
335 / 2018\end{array}$ \\
\hline $\begin{array}{l}\text { Paula Verónica } \\
\text { GONZÁLEZ }\end{array}$ & Poder Judicial & $\begin{array}{l}\text { JUEZA DEL JUZGADO } \\
\text { NACIONAL EN LO CRIMINAL } \\
\text { Y CORRECCIONAL N } 40 \text { DE LA } \\
\text { CAPITAL FEDERAL }\end{array}$ & $\begin{array}{c}\text { Decreto } \\
340 / 2018\end{array}$ \\
\hline $\begin{array}{l}\text { Mariana Julieta } \\
\text { FORTUNA }\end{array}$ & Poder Judicial & $\begin{array}{l}\text { JUEZA DEL JUZGADO } \\
\text { NACIONAL DE PRIMERA } \\
\text { INSTANCIA EN LO CIVIL Nº } 38 \\
\text { DE LA CAPITAL FEDERAL }\end{array}$ & $\begin{array}{c}\text { Decreto } \\
380 / 2018\end{array}$ \\
\hline $\begin{array}{l}\text { Celia Elsa } \\
\text { GIORDANINO }\end{array}$ & Poder Judicial & $\begin{array}{l}\text { JUEZA DEL JUZGADO } \\
\text { NACIONAL DE PRIMERA } \\
\text { INSTANCIA EN LO CIVIL No } 106 \\
\text { DE LA CAPITAL FEDERAL }\end{array}$ & $\begin{array}{c}\text { Decreto } \\
378 / 2018\end{array}$ \\
\hline $\begin{array}{l}\text { Ana Paula } \\
\text { GARONA } \\
\text { DUPUIS }\end{array}$ & Poder Judicial & $\begin{array}{l}\text { JUEZA DEL JUZGADO } \\
\text { NACIONAL DE PRIMERA } \\
\text { INSTANCIA EN LO CIVIL N } 87 \\
\text { DE LA CAPITAL FEDERAL }\end{array}$ & $\begin{array}{c}\text { Decreto } \\
379 / 2018\end{array}$ \\
\hline $\begin{array}{l}\text { Diego Martín } \\
\text { CORIA }\end{array}$ & Poder Judicial & $\begin{array}{l}\text { JUEZ DEL JUZGADO NACIONAL } \\
\text { DE PRIMERA INSTANCIA EN } \\
\text { LO CIVIL N } 76 \text { DE LA CAPITAL } \\
\text { FEDERAL }\end{array}$ & $\begin{array}{c}\text { Decreto } \\
381 / 2018\end{array}$ \\
\hline $\begin{array}{l}\text { Cristóbal } \\
\text { LLORENTE }\end{array}$ & Poder Judicial & $\begin{array}{l}\text { JUEZ DEL JUZGADO NACIONAL } \\
\text { DE PRIMERA INSTANCIA EN } \\
\text { LO CIVIL N }{ }^{0} 83 \text { DE LA CAPITAL } \\
\text { FEDERAL }\end{array}$ & $\begin{array}{c}\text { Decreto } \\
382 / 2018\end{array}$ \\
\hline $\begin{array}{l}\text { Myriam Marisa } \\
\text { CATALDI }\end{array}$ & Poder Judicial & $\begin{array}{l}\text { JUEZA DEL JUZGADO } \\
\text { NACIONAL DE PRIMERA } \\
\text { INSTANCIA EN LO CIVIL N }{ }^{0} 7 \text { DE } \\
\text { LA CAPITAL FEDERAL }\end{array}$ & $\begin{array}{c}\text { Decreto } \\
383 / 2018\end{array}$ \\
\hline $\begin{array}{l}\text { Agustina DÍAZ } \\
\text { CORDERO }\end{array}$ & Poder Judicial & $\begin{array}{l}\text { JUEZA DEL JUZGADO } \\
\text { NACIONAL DE PRIMERA } \\
\text { INSTANCIA EN LO CIVIL N } 23 \\
\text { DE LA CAPITAL FEDERAL }\end{array}$ & $\begin{array}{c}\text { Decreto } \\
374 / 2018\end{array}$ \\
\hline
\end{tabular}




\begin{tabular}{|c|c|c|c|}
\hline Nombre & Organismo & Cargo & Decreto \\
\hline $\begin{array}{l}\text { María Victoria } \\
\text { FAMÁ }\end{array}$ & Poder Judicial & $\begin{array}{l}\text { JUEZA DEL JUZGADO } \\
\text { NACIONAL DE PRIMERA } \\
\text { INSTANCIA EN LO CIVIL Nº } 92 \\
\text { DE LA CAPITAL FEDERAL }\end{array}$ & $\begin{array}{c}\text { Decreto } \\
375 / 2018\end{array}$ \\
\hline $\begin{array}{l}\text { María Gabriela } \\
\text { VERO }\end{array}$ & Poder Judicial & $\begin{array}{l}\text { JUEZA DEL JUZGADO } \\
\text { NACIONAL DE PRIMERA } \\
\text { INSTANCIA EN LO CIVIL No } 56 \\
\text { DE LA CAPITAL FEDERAL, } \\
\end{array}$ & $\begin{array}{c}\text { Decreto } \\
377 / 2018\end{array}$ \\
\hline $\begin{array}{l}\text { Eduardo } \\
\text { Guillermo } \\
\text { FARAH }\end{array}$ & Poder Judicial & $\begin{array}{l}\text { Trasládase de la CÁMARA } \\
\text { NACIONAL DE APELACIONES } \\
\text { EN LO CRIMINAL Y } \\
\text { CORRECCIONAL FEDERAL DE LA } \\
\text { CAPITAL FEDERAL, SALA II al } \\
\text { TRIBUNAL ORAL EN LO PENAL } \\
\text { ECONÓMICO N } 1\end{array}$ & $\begin{array}{c}\text { Decreto } \\
429 / 2018\end{array}$ \\
\hline $\begin{array}{l}\text { Mariano } \\
\text { LLORENS }\end{array}$ & Poder Judicial & $\begin{array}{l}\text { VOCAL DE LA CÁMARA } \\
\text { NACIONAL DE APELACIONES } \\
\text { EN LO CRIMINAL Y } \\
\text { CORRECCIONAL FEDERAL DE LA } \\
\text { CAPITAL FEDERAL, SALA I }\end{array}$ & $\begin{array}{c}\text { Decreto } \\
514 / 2018\end{array}$ \\
\hline $\begin{array}{l}\text { Hernán Martín } \\
\text { LÓPEZ }\end{array}$ & Poder Judicial & $\begin{array}{l}\text { VOCAL DE LA CÁMARA } \\
\text { NACIONAL DE APELACIONES } \\
\text { EN LO CRIMINAL Y } \\
\text { CORRECCIONAL DE LA CAPITAL } \\
\text { FEDERAL, VOCALIIA N }{ }^{\circ} 16\end{array}$ & $\begin{array}{c}\text { Decreto } \\
533 / 2018\end{array}$ \\
\hline $\begin{array}{l}\text { Magdalena } \\
\text { LAIÑO DONDIZ }\end{array}$ & Poder Judicial & $\begin{array}{l}\text { VOCAL DE LA CÁMARA } \\
\text { NACIONAL DE APELACIONES } \\
\text { EN LO CRIMINAL Y } \\
\text { CORRECCIONAL DE LA CAPITAL } \\
\text { FEDERAL, VOCALIIA N }{ }^{\circ} 3 \\
\end{array}$ & $\begin{array}{c}\text { Decreto } \\
534 / 2018\end{array}$ \\
\hline $\begin{array}{l}\text { Mariana } \\
\text { Graciela } \\
\text { CALLEGARI }\end{array}$ & Poder Judicial & $\begin{array}{l}\text { JUEZA DEL JUZGADO } \\
\text { NACIONAL DE PRIMERA } \\
\text { INSTANCIA EN LO CIVIL N }{ }^{0} 59 \\
\text { DE LA CAPITAL FEDERAL }\end{array}$ & $\begin{array}{c}\text { Decreto } \\
518 / 2018\end{array}$ \\
\hline
\end{tabular}




\begin{tabular}{|c|c|c|c|}
\hline Nombre & Organismo & Cargo & Decreto \\
\hline $\begin{array}{l}\text { Analía Victoria } \\
\text { ROMERO }\end{array}$ & Poder Judicial & $\begin{array}{l}\text { JUEZA DEL JUZGADO } \\
\text { NACIONAL DE PRIMERA } \\
\text { INSTANCIA EN LO CIVIL N } 40 \\
\text { DE LA CAPITAL FEDERAL }\end{array}$ & $\begin{array}{c}\text { Decreto } \\
519 / 2018\end{array}$ \\
\hline $\begin{array}{l}\text { Sebastián } \\
\text { Francisco FONT }\end{array}$ & Poder Judicial & $\begin{array}{l}\text { JUEZ DEL JUZGADO NACIONAL } \\
\text { DE PRIMERA INSTANCIA EN } \\
\text { LO CIVIL N } 36 \text { DE LA CAPITAL } \\
\text { FEDERAL }\end{array}$ & $\begin{array}{c}\text { Decreto } \\
520 / 2018\end{array}$ \\
\hline $\begin{array}{l}\text { Christian } \\
\text { Ricardo PETTIS }\end{array}$ & Poder Judicial & $\begin{array}{l}\text { JUEZ DEL JUZGADO NACIONAL } \\
\text { DE PRIMERA INSTANCIA EN } \\
\text { LO CIVIL N } 98 \text { DE LA CAPITAL } \\
\text { FEDERAL }\end{array}$ & $\begin{array}{c}\text { Decreto } \\
521 / 2018\end{array}$ \\
\hline $\begin{array}{l}\text { Cecilia Beatriz } \\
\text { KANDUS }\end{array}$ & Poder Judicial & $\begin{array}{l}\text { JUEZA DEL JUZGADO } \\
\text { NACIONAL DE PRIMERA } \\
\text { INSTANCIA EN LO CIVIL N } 24 \\
\text { DE LA CAPITAL FEDERAL }\end{array}$ & $\begin{array}{c}\text { Decreto } \\
522 / 2018\end{array}$ \\
\hline $\begin{array}{l}\text { Santiago } \\
\text { STRASSERA }\end{array}$ & Poder Judicial & $\begin{array}{l}\text { JUEZ DEL JUZGADO NACIONAL } \\
\text { DE PRIMERA INSTANCIA EN } \\
\text { LO CIVIL N } 37 \text { DE LA CAPITAL } \\
\text { FEDERAL }\end{array}$ & $\begin{array}{c}\text { Decreto } \\
524 / 2018\end{array}$ \\
\hline $\begin{array}{l}\text { María Elisa } \\
\text { ARIAS }\end{array}$ & Poder Judicial & $\begin{array}{l}\text { JUEZA DEL JUZGADO } \\
\text { NACIONAL DE PRIMERA } \\
\text { INSTANCIA EN LO CIVIL No } 12 \\
\text { DE LA CAPITAL FEDERAL }\end{array}$ & $\begin{array}{c}\text { Decreto } \\
523 / 2018\end{array}$ \\
\hline $\begin{array}{l}\text { María Laura } \\
\text { RAGONI }\end{array}$ & Poder Judicial & $\begin{array}{l}\text { JUEZA DEL JUZGADO } \\
\text { NACIONAL DE PRIMERA } \\
\text { INSTANCIA EN LO CIVIL Nº } 89 \\
\text { DE LA CAPITAL FEDERAL }\end{array}$ & $\begin{array}{c}\text { Decreto } \\
526 / 2018\end{array}$ \\
\hline $\begin{array}{l}\text { Paula Andrea } \\
\text { CASTRO }\end{array}$ & Poder Judicial & $\begin{array}{l}\text { JUEZA DEL JUZGADO } \\
\text { NACIONAL DE PRIMERA } \\
\text { INSTANCIA EN LO CIVIL Nº } 93 \\
\text { DE LA CAPITAL FEDERAL }\end{array}$ & $\begin{array}{c}\text { Decreto } \\
529 / 2018\end{array}$ \\
\hline $\begin{array}{l}\text { Aldo Mario DI } \\
\text { VITO }\end{array}$ & Poder Judicial & $\begin{array}{l}\text { JUEZ DEL JUZGADO NACIONAL } \\
\text { DE PRIMERA INSTANCIA EN } \\
\text { LO CIVIL N } 71 \text { DE LA CAPITAL } \\
\text { FEDERAL }\end{array}$ & $\begin{array}{c}\text { Decreto } \\
527 / 2018\end{array}$ \\
\hline
\end{tabular}




\begin{tabular}{|c|c|c|c|}
\hline Nombre & Organismo & Cargo & Decreto \\
\hline $\begin{array}{l}\text { Juan Martín } \\
\text { ALTERINI }\end{array}$ & Poder Judicial & $\begin{array}{l}\text { JUEZ DEL JUZGADO NACIONAL } \\
\text { DE PRIMERA INSTANCIA EN } \\
\text { LO CIVIL N }{ }^{\circ} 27 \text { DE LA CAPITAL } \\
\text { FEDERAL }\end{array}$ & $\begin{array}{c}\text { Decreto } \\
525 / 2018\end{array}$ \\
\hline $\begin{array}{l}\text { Viviana Silvia } \\
\text { TORELLO }\end{array}$ & Poder Judicial & $\begin{array}{l}\text { JUEZA DEL JUZGADO } \\
\text { NACIONAL DE PRIMERA } \\
\text { INSTANCIA EN LO CIVIL Nº } 49 \\
\text { DE LA CAPITAL FEDERAL }\end{array}$ & $\begin{array}{c}\text { Decreto } \\
528 / 2018\end{array}$ \\
\hline $\begin{array}{l}\text { Ignacio } \\
\text { RODRÍGUEZ } \\
\text { VARELA }\end{array}$ & Poder Judicial & $\begin{array}{l}\text { VOCAL DE LA CÁMARA } \\
\text { NACIONAL DE APELACIONES } \\
\text { EN LO CRIMINAL Y } \\
\text { CORRECCIONAL DE LA CAPITAL } \\
\text { FEDERAL, VOCALIIA N } 10\end{array}$ & $\begin{array}{c}\text { Decreto } \\
530 / 2018\end{array}$ \\
\hline $\begin{array}{l}\text { Lino Claudio } \\
\text { MIRABELLI }\end{array}$ & Poder Judicial & $\begin{array}{l}\text { JUEZ DEL JUZGADO FEDERAL } \\
\text { DE PRIMERA INSTANCIA EN LO } \\
\text { CRIMINAL Y CORRECCIONAL } \\
\text { No } 2 \text { DE SAN ISIDRO, } \\
\text { PROVINCIA DE BUENOS AIRES }\end{array}$ & $\begin{array}{c}\text { Decreto } \\
531 / 2018\end{array}$ \\
\hline $\begin{array}{l}\text { Liliana María } \\
\text { Leonor HEILAND }\end{array}$ & Poder Judicial & $\begin{array}{l}\text { VOCAL DE LA CÁMARA } \\
\text { NACIONAL DE APELACIONES } \\
\text { EN LO CONTENCIOSO } \\
\text { ADMINISTRATIVO FEDERAL DE } \\
\text { LA CAPITAL FEDERAL, SALA I, }\end{array}$ & $\begin{array}{c}\text { Decreto } \\
546 / 2018\end{array}$ \\
\hline $\begin{array}{l}\text { Silvia Mónica } \\
\text { FARIÑA }\end{array}$ & Poder Judicial & $\begin{array}{l}\text { VOCAL DE LA CÁMARA } \\
\text { FEDERAL DE APELACIONES DE } \\
\text { BAHÍA BLANCA, PROVINCIA DE } \\
\text { BUENOS AIRES, }\end{array}$ & $\begin{array}{c}\text { Decreto } \\
548 / 2018\end{array}$ \\
\hline $\begin{array}{l}\text { Pablo Esteban } \\
\text { LARRIERA }\end{array}$ & Poder Judicial & $\begin{array}{l}\text { VOCAL DE LA CÁMARA } \\
\text { FEDERAL DE APELACIONES DE } \\
\text { BAHÍA BLANCA, PROVINCIA DE } \\
\text { BUENOS AIRES }\end{array}$ & $\begin{array}{c}\text { Decreto } \\
547 / 2018\end{array}$ \\
\hline $\begin{array}{l}\text { José Luis } \\
\text { AGÜERO ITURBE }\end{array}$ & $\begin{array}{l}\text { Ministerio } \\
\text { Público de la } \\
\text { Nación } \\
\end{array}$ & $\begin{array}{l}\text { FISCAL GENERAL ADJUNTO DE } \\
\text { LA PROCURACIÓN GENERAL DE } \\
\text { LA NACIÓN }\end{array}$ & $\begin{array}{c}\text { Decreto } \\
549 / 2018\end{array}$ \\
\hline $\begin{array}{l}\text { Silvina } \\
\text { MAYORGA }\end{array}$ & Poder Judicial & $\begin{array}{l}\text { JUEZA DE CÁMARA DEL } \\
\text { TRIBUNAL ORAL EN LO } \\
\text { CRIMINAL FEDERAL N } 10 \text { DE } \\
\text { SAN MARTÍN }\end{array}$ & $\begin{array}{c}\text { Decreto } \\
560 / 2018\end{array}$ \\
\hline
\end{tabular}




\begin{tabular}{|c|c|c|c|}
\hline Nombre & Organismo & Cargo & Decreto \\
\hline $\begin{array}{l}\text { Roberto Daniel } \\
\text { AMABILE }\end{array}$ & Poder Judicial & \begin{tabular}{|l|} 
VOCAL DE LA CÁMARA \\
FEDERAL DE APELACIONES DE \\
BAHÍA BLANCA, PROVINCIA DE \\
BUENOS AIRES
\end{tabular} & $\begin{array}{l}\text { Decreto } \\
565 / 2018\end{array}$ \\
\hline $\begin{array}{l}\text { Matías } \\
\text { Alejandro } \\
\text { MANCINI }\end{array}$ & Poder Judicial & $\begin{array}{l}\text { JUEZ DE CÁMARA DEL } \\
\text { TRIBUNAL ORAL EN LO } \\
\text { CRIMINAL FEDERAL N }{ }^{0} 4 \text { DE } \\
\text { SAN MARTÍN }\end{array}$ & $\begin{array}{l}\text { Decreto } \\
570 / 2018\end{array}$ \\
\hline $\begin{array}{l}\text { Walter Antono } \\
\text { BENDITTI }\end{array}$ & Poder Judicial & $\begin{array}{l}\text { JUEZ DE CÁMARA DEL } \\
\text { TRIBUNAL ORAL EN LO } \\
\text { CRIMINAL FEDERAL N } 2 \text { DE } \\
\text { SAN MARTÍN, PROVINCIA DE } \\
\text { BUENOS AIRES }\end{array}$ & $\begin{array}{l}\text { Decreto } \\
571 / 2018\end{array}$ \\
\hline $\begin{array}{l}\text { Leandro Sergio } \\
\text { PICADO }\end{array}$ & Poder Judicial & \begin{tabular}{|l|} 
VOCAL DE LA CÁMARA \\
FEDERAL DE APELACIONES DE \\
BAHÍA BLANCA, PROVINCIA DE \\
BUENOS AIRES
\end{tabular} & $\begin{array}{l}\text { Decreto } \\
572 / 2018\end{array}$ \\
\hline $\begin{array}{l}\text { Julio Enrique } \\
\text { Enzo AGNOLI }\end{array}$ & $\begin{array}{l}\text { Ministerio } \\
\text { Público de la } \\
\text { Defensa } \\
\end{array}$ & $\begin{array}{l}\text { DEFENSOR PÚBLICO OFICIAL } \\
\text { ANTE EL TRIBUNAL ORAL EN LO } \\
\text { CRIMINAL FEDERAL DE SANTA FE }\end{array}$ & $\begin{array}{c}\text { Decreto } \\
566 / 2018\end{array}$ \\
\hline $\begin{array}{l}\text { Santiago } \\
\text { ROLDÁN }\end{array}$ & $\begin{array}{l}\text { Ministerio } \\
\text { Público Fiscal }\end{array}$ & $\begin{array}{l}\text { FISCAL DE LA PROCURACIÓN } \\
\text { GENERAL DE LA NACIÓN }\end{array}$ & $\begin{array}{c}\text { Decreto } \\
563 / 2018\end{array}$ \\
\hline $\begin{array}{l}\text { Cecilia Patricia } \\
\text { INCARDONA }\end{array}$ & $\begin{array}{l}\text { Ministerio } \\
\text { Público Fiscal }\end{array}$ & $\begin{array}{l}\text { FISCAL ANTE LOS JUZGADOS } \\
\text { FEDERALES DE PRIMERA } \\
\text { INSTANCIA DE LOMAS DE } \\
\text { ZAMORA, PROVINCIA DE } \\
\text { BUENOS AIRES, FISCALÍA N }{ }^{0} 2\end{array}$ & $\begin{array}{c}\text { Decreto } \\
564 / 2018\end{array}$ \\
\hline $\begin{array}{l}\text { Osvaldo Onofre } \\
\text { ÁLVAREZ }\end{array}$ & Poder Judicial & $\begin{array}{l}\text { Trasládase de la CÁMARA } \\
\text { NACIONAL DE APELACIONES } \\
\text { EN LO CIVIL DE LA CAPITAL } \\
\text { FEDERAL, SALA D a la CÁMARA } \\
\text { NACIONAL DE APELACIONES } \\
\text { EN LO CIVIL DE LA CAPITAL } \\
\text { FEDERAL, SALA K, } \\
\end{array}$ & $\begin{array}{c}\text { Decreto } \\
590 / 2018\end{array}$ \\
\hline \begin{tabular}{|l|} 
Diego Gustavo \\
BARROETAVEÑA
\end{tabular} & Poder Judicial & $\begin{array}{l}\text { VOCAL DE LA CÁMARA } \\
\text { FEDERAL DE CASACIÓN PENAL, } \\
\text { VOCALÍA N } 5\end{array}$ & $\begin{array}{l}\text { Decreto } \\
627 / 2018\end{array}$ \\
\hline
\end{tabular}




\begin{tabular}{|c|c|c|c|}
\hline Nombre & Organismo & Cargo & Decreto \\
\hline $\begin{array}{l}\text { Daniel Antonio } \\
\text { PETRONE }\end{array}$ & Poder Judicial & $\begin{array}{l}\text { VOCAL DE LA CÁMARA } \\
\text { FEDERAL DE CASACIÓN PENAL, } \\
\text { VOCALÍA N² } 2\end{array}$ & $\begin{array}{l}\text { Decreto } \\
626 / 2018\end{array}$ \\
\hline $\begin{array}{l}\text { Carlos Alberto } \\
\text { MAHÍQUES }\end{array}$ & Poder Judicial & $\begin{array}{l}\text { Trasládase de la CÁMARA } \\
\text { NACIONAL DE CASACIÓN EN } \\
\text { LO CRIMINAL Y CORRECCIONAL } \\
\text { DE LA CAPITAL FEDERAL, SALA } \\
\text { III, A LA CÁMARA FEDERAL DE } \\
\text { CASACIÓN PENAL, VOCALÍA VII }\end{array}$ & $\begin{array}{c}\text { Decreto } \\
625 / 2018\end{array}$ \\
\hline $\begin{array}{l}\text { Guillermo Jorge } \\
\text { YACOBUCCI }\end{array}$ & Poder Judicial & $\begin{array}{l}\text { VOCAL DE LA CÁMARA } \\
\text { FEDERAL DE CASACIÓN PENAL, } \\
\text { VOCALÍA N }{ }^{0} 12\end{array}$ & $\begin{array}{c}\text { Decreto } \\
635 / 2018\end{array}$ \\
\hline $\begin{array}{l}\text { Alejandro Javier } \\
\text { SANTAMARÍA }\end{array}$ & Poder Judicial & $\begin{array}{l}\text { JUEZ DEL JUZGADO NACIONAL } \\
\text { DE PRIMERA INSTANCIA EN } \\
\text { LO CIVIL No } 15 \text { DE LA CAPITAL } \\
\text { FEDERAL }\end{array}$ & $\begin{array}{c}\text { Decreto } \\
644 / 2018\end{array}$ \\
\hline $\begin{array}{l}\text { Eduardo } \\
\text { Alejandro } \\
\text { MAGGIORA }\end{array}$ & Poder Judicial & $\begin{array}{l}\text { JUEZ DEL JUZGADO NACIONAL } \\
\text { DE PRIMERA INSTANCIA EN } \\
\text { LO CIVIL N } 42 \text { DE LA CAPITAL } \\
\text { FEDERAL }\end{array}$ & $\begin{array}{c}\text { Decreto } \\
645 / 2018\end{array}$ \\
\hline $\begin{array}{l}\text { Paula Emilia } \\
\text { FERNÁNDEZ }\end{array}$ & Poder Judicial & $\begin{array}{l}\text { JUEZA DEL JUZGADO } \\
\text { NACIONAL DE PRIMERA } \\
\text { INSTANCIA EN LO CIVIL Nº } 18 \\
\text { DE LA CAPITAL FEDERAL } \\
\end{array}$ & $\begin{array}{c}\text { Decreto } \\
646 / 2018\end{array}$ \\
\hline $\begin{array}{l}\text { Mario Alberto } \\
\text { VILLAR }\end{array}$ & $\begin{array}{l}\text { Ministerio } \\
\text { Público Fiscal }\end{array}$ & $\begin{array}{l}\text { FISCAL GENERAL ANTE } \\
\text { LA CÁMARA FEDERAL DE } \\
\text { CASACIÓN PENAL, FISCALÍA No } 1\end{array}$ & $\begin{array}{c}\text { Decreto } \\
643 / 2018\end{array}$ \\
\hline $\begin{array}{l}\text { Daniel Omar } \\
\text { GUTIÉRREZ }\end{array}$ & Poder Judicial & $\begin{array}{l}\text { JUEZ DE CÁMARA DEL TRIBUNAL } \\
\text { ORAL EN LO CRIMINAL FEDERAL } \\
\text { NN1 DE SAN MARTÍN }\end{array}$ & $\begin{array}{c}\text { Decreto } \\
657 / 2018\end{array}$ \\
\hline $\begin{array}{l}\text { Enrique } \\
\text { LILLJEDAHL }\end{array}$ & Poder Judicial & $\begin{array}{l}\text { JUEZ DE CÁMARA DEL TRIBUNAL } \\
\text { ORAL EN LO CRIMINAL FEDERAL } \\
\text { DE CATAMARCA, }\end{array}$ & $\begin{array}{c}\text { Decreto } \\
661 / 2018\end{array}$ \\
\hline $\begin{array}{l}\text { María Eugenia } \\
\text { NELLI }\end{array}$ & Poder Judicial & $\begin{array}{l}\text { JUEZA DEL JUZGADO } \\
\text { NACIONAL DE PRIMERA } \\
\text { INSTANCIA EN LO CIVIL Nº } 2 \text { DE } \\
\text { LA CAPITAL FEDERAL }\end{array}$ & $\begin{array}{l}\text { Decreto } \\
662 / 2018\end{array}$ \\
\hline
\end{tabular}




\begin{tabular}{|c|c|c|c|}
\hline Nombre & Organismo & Cargo & Decreto \\
\hline $\begin{array}{l}\text { Federico José } \\
\text { IUSPA }\end{array}$ & $\begin{array}{l}\text { Ministerio } \\
\text { Público Fiscal }\end{array}$ & $\begin{array}{l}\text { FISCAL ANTE LOS JUZGADOS } \\
\text { FEDERALES DE PRIMERA } \\
\text { INSTANCIA EN LO CRIMINAL } \\
\text { Y CORRECCIONAL DE SAN } \\
\text { ISIDRO, PROVINCIA DE BUENOS } \\
\text { AIRES, FISCALÍA N }{ }^{\circ} 1\end{array}$ & $\begin{array}{c}\text { Decreto } \\
659 / 2018\end{array}$ \\
\hline $\begin{array}{l}\text { Sebastián } \\
\text { Alberto } \\
\text { BRINGAS }\end{array}$ & $\begin{array}{l}\text { Ministerio } \\
\text { Público Fiscal }\end{array}$ & $\begin{array}{l}\text { FISCAL ANTE EL JUZGADO } \\
\text { FEDERAL DE PRIMERA } \\
\text { INSTANCIA DE CAMPANA, } \\
\text { PROVINCIA DE BUENOS AIRES }\end{array}$ & $\begin{array}{c}\text { Decreto } \\
660 / 2018\end{array}$ \\
\hline $\begin{array}{l}\text { Mariana SAIZ } \\
\text { CAEIRO }\end{array}$ & Poder Judicial & $\begin{array}{l}\text { JUEZA DEL JUZGADO } \\
\text { NACIONAL DE PRIMERA } \\
\text { INSTANCIA DEL TRABAJO Nº } 58 \\
\text { DE LA CAPITAL FEDERAL }\end{array}$ & $\begin{array}{c}\text { Decreto } \\
669 / 2018\end{array}$ \\
\hline $\begin{array}{l}\text { Ricardo Darío } \\
\text { AGUGLIARO }\end{array}$ & Poder Judicial & $\begin{array}{l}\text { JUEZ DEL JUZGADO NACIONAL } \\
\text { DE PRIMERA INSTANCIA EN } \\
\text { LO CIVIL N } 107 \text { DE LA CAPITAL } \\
\text { FEDERAL }\end{array}$ & $\begin{array}{c}\text { Decreto } \\
668 / 2018\end{array}$ \\
\hline $\begin{array}{l}\text { Marcelo Claudio } \\
\text { FERNÁNDEZ }\end{array}$ & Poder Judicial & $\begin{array}{l}\text { JUEZ DEL JUZGADO NACIONAL } \\
\text { DE PRIMERA INSTANCIA DEL } \\
\text { TRABAJO Nº } 25 \text { DE LA CAPITAL } \\
\text { FEDERAL }\end{array}$ & $\begin{array}{c}\text { Decreto } \\
667 / 2018\end{array}$ \\
\hline $\begin{array}{l}\text { Gabriela Susana } \\
\text { CRUZ DEVOTO }\end{array}$ & Poder Judicial & $\begin{array}{l}\text { JUEZA DEL JUZGADO } \\
\text { NACIONAL DE PRIMERA } \\
\text { INSTANCIA DEL TRABAJO Nº } 65 \\
\text { DE LA CAPITAL FEDERAL }\end{array}$ & $\begin{array}{c}\text { Decreto } \\
666 / 2018\end{array}$ \\
\hline $\begin{array}{l}\text { Esteban Carlos } \\
\text { RODRÍGUEZ } \\
\text { EGGERS }\end{array}$ & Poder Judicial & $\begin{array}{l}\text { JUEZ DE CÁMARA DEL } \\
\text { TRIBUNAL ORAL EN LO } \\
\text { CRIMINAL FEDERAL Nº } 4 \text { DE } \\
\text { SAN MARTÍN } \\
\end{array}$ & $\begin{array}{c}\text { Decreto } \\
670 / 2018\end{array}$ \\
\hline $\begin{array}{l}\text { Pablo Guillermo } \\
\text { LUCERO }\end{array}$ & Poder Judicial & $\begin{array}{l}\text { VOCAL DE LA CÁMARA } \\
\text { NACIONAL DE APELACIONES } \\
\text { EN LO CRIMINAL Y } \\
\text { CORRECCIONAL DE LA CAPITAL } \\
\text { FEDERAL, VOCALIIA N }{ }^{\circ} 4\end{array}$ & $\begin{array}{c}\text { Decreto } \\
673 / 2018\end{array}$ \\
\hline
\end{tabular}




\begin{tabular}{|c|c|c|c|}
\hline Nombre & Organismo & Cargo & Decreto \\
\hline $\begin{array}{l}\text { Ricardo Ángel } \\
\text { BASÍLICO }\end{array}$ & Poder Judicial & $\begin{array}{l}\text { Trasládase del TRIBUNAL } \\
\text { ORAL EN LO CRIMINAL Y } \\
\text { CORRECCIONAL N } 8 \text { DE LA } \\
\text { CAPITAL FEDERAL, al TRIBUNAL } \\
\text { ORAL EN LO CRIMINAL FEDERAL } \\
\text { No } 1 \text { DE LA CAPITAL FEDERAL }\end{array}$ & $674 / 2018$ \\
\hline $\begin{array}{l}\text { Pablo Daniel } \\
\text { BERTUZZI }\end{array}$ & Poder Judicial & $\begin{array}{l}\text { TRIBUNAL ORAL EN LO } \\
\text { CRIMINAL FEDERAL N }{ }^{\circ} 4 \\
\text { DE LA CAPITAL FEDERAL a } \\
\text { la CÁMARA NACIONAL DE } \\
\text { APELACIONES EN LO CRIMINAL } \\
\text { Y CORRECCIONAL FEDERAL DE } \\
\text { LA CAPITAL FEDERAL, SALA I }\end{array}$ & $\begin{array}{c}\text { Decreto } \\
835 / 2018\end{array}$ \\
\hline $\begin{array}{l}\text { Germán Andrés } \\
\text { CASTELLI }\end{array}$ & Poder Judicial & $\begin{array}{l}\text { Trasládese TRIBUNAL ORAL EN } \\
\text { LO CRIMINAL FEDERAL N } 3 \text { DE } \\
\text { SAN MARTÍN, PROVINCIA DE } \\
\text { BUENOS AIRES al TRIBUNAL } \\
\text { ORAL EN LO CRIMINAL FEDERAL } \\
\text { No } 7 \text { DE LA CAPITAL FEDERAL }\end{array}$ & $\begin{array}{c}\text { Decreto } \\
\text { 902/2018 }\end{array}$ \\
\hline Pablo TRíPOLI & Poder Judicial & $\begin{array}{l}\text { VOCAL DE LA CÁMARA } \\
\text { NACIONAL DE APELACIONES } \\
\text { EN LO CIVIL DE LA CAPITAL } \\
\text { FEDERAL, SALA C }\end{array}$ & $\begin{array}{l}\text { Decreto } \\
937 / 2018\end{array}$ \\
\hline $\begin{array}{l}\text { Santiago } \\
\text { Ulpiano } \\
\text { MARTÍNEZ }\end{array}$ & $\begin{array}{l}\text { Ministerio } \\
\text { Público Fiscal }\end{array}$ & $\begin{array}{l}\text { FISCAL ANTE LOS JUZGADOS } \\
\text { FEDERALES DE PRIMERA } \\
\text { INSTANCIA DE BAHIIA BLANCA, } \\
\text { PROVINCIA DE BUENOS AIRES, } \\
\text { FISCALIA N }{ }^{0} 2\end{array}$ & \\
\hline $\begin{array}{l}\text { Carlos Manuel } \\
\text { GRECCO }\end{array}$ & Poder Judicial & $\begin{array}{l}\text { VOCAL DE LA CÁMARA } \\
\text { NACIONAL DE APELACIONES } \\
\text { EN LO CONTENCIOSO } \\
\text { ADMINISTRATIVO FEDERAL DE } \\
\text { LA CAPITAL FEDERAL, SALA III }\end{array}$ & $\begin{array}{c}\text { Decreto } \\
957 / 2018\end{array}$ \\
\hline $\begin{array}{l}\text { Juan Manuel } \\
\text { CONVERSET }\end{array}$ & Poder Judicial & $\begin{array}{l}\text { VOCAL DE LA CÁMARA } \\
\text { NACIONAL DE APELACIONES } \\
\text { EN LO CIVIL DE LA CAPITAL } \\
\text { FEDERAL, SALA C }\end{array}$ & $\begin{array}{c}\text { Decreto } \\
941 / 2018\end{array}$ \\
\hline
\end{tabular}




\begin{tabular}{|c|c|c|c|}
\hline Nombre & Organismo & Cargo & Decreto \\
\hline $\begin{array}{l}\text { Juan Pablo } \\
\text { RODRÍGUEZ }\end{array}$ & Poder Judicial & $\begin{array}{l}\text { VOCAL DE LA CÁMARA } \\
\text { NACIONAL DE APELACIONES } \\
\text { EN LO CIVIL DE LA CAPITAL } \\
\text { FEDERAL, SALA I }\end{array}$ & $\begin{array}{l}\text { Decreto } \\
942 / 2018\end{array}$ \\
\hline $\begin{array}{l}\text { Gonzalo Matías } \\
\text { OLIVER DE } \\
\text { TEZANOS }\end{array}$ & Poder Judicial & $\begin{array}{l}\text { JUEZ DEL JUZGADO NACIONAL } \\
\text { DE MENORES N }{ }^{\circ} 5 \text { DE LA } \\
\text { CAPITAL FEDERAL }\end{array}$ & $\begin{array}{l}\text { Decreto } \\
943 / 2018\end{array}$ \\
\hline $\begin{array}{l}\text { Silvia Patricia } \\
\text { BERMEJO }\end{array}$ & Poder Judicial & $\begin{array}{l}\text { VOCAL DE LA CÁMARA } \\
\text { NACIONAL DE APELACIONES } \\
\text { EN LO CIVIL DE LA CAPITAL } \\
\text { FEDERAL, SALA K }\end{array}$ & $\begin{array}{l}\text { Decreto } \\
944 / 2018\end{array}$ \\
\hline $\begin{array}{l}\text { Carlos Federico } \\
\text { COCIANCICH }\end{array}$ & Poder Judicial & $\begin{array}{l}\text { JUEZ DEL JUZGADO NACIONAL } \\
\text { DE MENORES N }{ }^{\circ} 6 \text { DE LA } \\
\text { CAPITAL FEDERAL }\end{array}$ & $\begin{array}{l}\text { Decreto } \\
947 / 2018\end{array}$ \\
\hline Axel VON LEERS & Poder Judicial & $\begin{array}{l}\text { JUEZ DEL JUZGADO NACIONAL } \\
\text { DE MENORES N }{ }^{\circ} 1 \text { DE LA } \\
\text { CAPITAL FEDERAL }\end{array}$ & $\begin{array}{l}\text { Decreto } \\
946 / 2018\end{array}$ \\
\hline $\begin{array}{l}\text { Mariano } \\
\text { CANDAL }\end{array}$ & Poder judicial & $\begin{array}{l}\text { JUZGADO NACIONAL DE } \\
\text { PRIMERA INSTANCIA DEL } \\
\text { TRABAJO N } 77 \text { DE LA CAPITAL } \\
\text { FEDERAL }\end{array}$ & $\begin{array}{c}\text { Decreto } \\
983 / 2018\end{array}$ \\
\hline $\begin{array}{l}\text { Eduardo } \\
\text { Guillermo } \\
\text { FARAH }\end{array}$ & Poder Judicial & 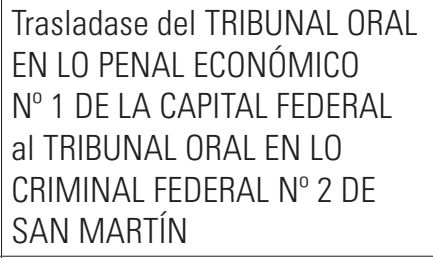 & $\begin{array}{l}\text { Decreto } \\
982 / 2018\end{array}$ \\
\hline $\begin{array}{l}\text { Pablo Gustavo } \\
\text { LAUFER }\end{array}$ & Poder Judicial & $\begin{array}{l}\text { Trasládase del TRIBUNAL } \\
\text { ORAL EN LO CRIMINAL Y } \\
\text { CORRECCIONAL No } 20 \text { DE LA } \\
\text { CAPITAL FEDERAL al TRIBUNAL } \\
\text { ORAL EN LO CRIMINAL Y } \\
\text { CORRECCIONAL N }{ }^{\circ} 4\end{array}$ & $\begin{array}{l}\text { Decreto } \\
1016 / 2018\end{array}$ \\
\hline
\end{tabular}




\begin{tabular}{|c|c|c|c|}
\hline Nombre & Organismo & Cargo & Decreto \\
\hline $\begin{array}{l}\text { Esteban Eduardo } \\
\text { HANSEN }\end{array}$ & Poder Judicial & $\begin{array}{l}\text { Trasládase del JUZGADO } \\
\text { FEDERAL DE PRIMERA } \\
\text { INSTANCIA DE LIBERTADOR } \\
\text { GENERAL SAN MARTÍN, } \\
\text { PROVINCIA DE JUJUY al } \\
\text { JUZGADO FEDERAL DE PRIMERA } \\
\text { INSTANCIA N } 10 \text { DE JUJUY, }\end{array}$ & $\begin{array}{c}\text { Decreto } \\
1167 / 2018\end{array}$ \\
\hline $\begin{array}{l}\text { Federico Hernán } \\
\text { VILLENA }\end{array}$ & Poder Judicial & $\begin{array}{l}\text { Trasládase del JUZGADO } \\
\text { FEDERAL DE PRIMERA } \\
\text { INSTANCIA DE MORENO, } \\
\text { PROVINCIA DE BUENOS AIRES } \\
\text { al JUZGADO FEDERAL DE } \\
\text { PRIMERA INSTANCIA EN LO } \\
\text { CRIMINAL Y CORRECCIONAL } \\
\text { No } 1 \text { DE LOMAS DE ZAMORA }\end{array}$ & $\begin{array}{c}\text { Decreto } \\
1168 / 2018\end{array}$ \\
\hline $\begin{array}{l}\text { Edmundo } \\
\text { RABBIONE }\end{array}$ & Poder Judicial & $\begin{array}{l}\text { JUEZ DEL JUZGADO } \\
\text { NACIONAL EN LO CRIMINAL } \\
\text { Y CORRECCIONAL Nº1 DE LA } \\
\text { CAPITAL FEDERAL }\end{array}$ & $\begin{array}{c}\text { Decreto } \\
1175 / 2018\end{array}$ \\
\hline $\begin{array}{l}\text { Carlos Javier } \\
\text { CARBAJO }\end{array}$ & Poder Judicial & $\begin{array}{l}\text { VOCAL DE LA CÁMARA } \\
\text { FEDERAL DE CASACIÓN PENAL, } \\
\text { VOCALÍA N } 3\end{array}$ & $\begin{array}{c}\text { Decreto } \\
1172 / 2018\end{array}$ \\
\hline $\begin{array}{l}\text { Juan José } \\
\text { BARIC }\end{array}$ & Poder Judicial & $\begin{array}{l}\text { JUEZ DEL JUZGADO FEDERAL } \\
\text { DE PRIMERA INSTANCIA DE } \\
\text { SANTA ROSA }\end{array}$ & $\begin{array}{l}\text { Decreto } \\
1174 / 2018\end{array}$ \\
\hline $\begin{array}{l}\text { Érica María } \\
\text { UHRLANDT }\end{array}$ & Poder Judicial & $\begin{array}{l}\text { JUEZA DEL JUZGADO } \\
\text { NACIONAL EN LO CRIMINAL } \\
\text { Y CORRECCIONAL N } 53 \text { DE LA } \\
\text { CAPITAL FEDERAL }\end{array}$ & $\begin{array}{c}\text { Decreto } \\
1185 / 2018\end{array}$ \\
\hline $\begin{array}{l}\text { Jorge Alejandro } \\
\text { ZABALA }\end{array}$ & Poder Judicial & $\begin{array}{l}\text { JUEZ DE CÁMARA DEL } \\
\text { TRIBUNAL ORAL EN LO PENAL } \\
\text { ECONÓMICO N } 3 \text { DE LA } \\
\text { CAPITAL FEDERAL }\end{array}$ & $\begin{array}{c}\text { Decreto } \\
1183 / 2018\end{array}$ \\
\hline $\begin{array}{l}\text { Diego GARCÍA } \\
\text { BERRO }\end{array}$ & Poder Judicial & $\begin{array}{l}\text { JUEZ DE CÁMARA DEL } \\
\text { TRIBUNAL ORAL EN LO PENAL } \\
\text { ECONÓMICO N } 1 \text { DE LA } \\
\text { CAPITAL FEDERAL }\end{array}$ & $\begin{array}{c}\text { Decreto } \\
1188 / 2018\end{array}$ \\
\hline
\end{tabular}




\begin{tabular}{|c|c|c|c|}
\hline Nombre & Organismo & Cargo & Decreto \\
\hline $\begin{array}{l}\text { Vanesa } \\
\text { Alejandra } \\
\text { PELUFFO }\end{array}$ & Poder Judicial & $\begin{array}{l}\text { JUEZA DEL JUZGADO } \\
\text { NACIONAL EN LO CRIMINAL } \\
\text { Y CORRECCIONAL N } 63 \text { DE LA } \\
\text { CAPITAL FEDERAL }\end{array}$ & $\begin{array}{c}\text { Decreto } \\
1189 / 2018\end{array}$ \\
\hline $\begin{array}{l}\text { María Fabiana } \\
\text { GALLETTI }\end{array}$ & Poder Judicial & $\begin{array}{l}\text { JUEZA DEL JUZGADO } \\
\text { NACIONAL EN LO CRIMINAL } \\
\text { Y CORRECCIONAL N } 57 \text { DE LA } \\
\text { CAPITAL FEDERAL }\end{array}$ & $\begin{array}{c}\text { Decreto } \\
1186 / 2018\end{array}$ \\
\hline $\begin{array}{l}\text { Alejandra } \\
\text { Mercedes } \\
\text { ALLIAUD }\end{array}$ & Poder Judicial & $\begin{array}{l}\text { JUEZA DEL JUZGADO } \\
\text { NACIONAL EN LO CRIMINAL } \\
\text { Y CORRECCIONAL N }{ }^{\circ} 55 \text { DE LA } \\
\text { CAPITAL FEDERAL }\end{array}$ & $\begin{array}{c}\text { Decreto } \\
1187 / 2018\end{array}$ \\
\hline $\begin{array}{l}\text { Gustavo } \\
\text { del Corazón } \\
\text { de Jesús } \\
\text { FRESNEDA }\end{array}$ & Poder Judicial & $\begin{array}{l}\text { UEZ DEL JUZGADO FEDERAL DE } \\
\text { PRIMERA INSTANCIA DE PASO } \\
\text { DE LOS LIBRES, PROVINCIA DE } \\
\text { CORRIENTES }\end{array}$ & $\begin{array}{c}\text { Decreto } \\
1191 / 2018\end{array}$ \\
\hline $\begin{array}{l}\text { Martín Carlos } \\
\text { DEL VISO }\end{array}$ & Poder Judicial & $\begin{array}{l}\text { JUEZ DEL JUZGADO } \\
\text { NACIONAL EN LO CRIMINAL } \\
\text { Y CORRECCIONAL N } 28 \text { DE LA } \\
\text { CAPITAL FEDERAL }\end{array}$ & $\begin{array}{c}\text { Decreto } \\
1182 / 2018\end{array}$ \\
\hline $\begin{array}{l}\text { Ignacio Carlos } \\
\text { FORNARI }\end{array}$ & Poder Judicial & $\begin{array}{l}\text { JUEZ DE CÁMARA DEL TRIBUNAL } \\
\text { ORAL EN LO PENAL ECONÓMICO } \\
\text { No } 1 \text { DE LA CAPITAL FEDERAL }\end{array}$ & $\begin{array}{c}\text { Decreto } \\
1190 / 2018\end{array}$ \\
\hline $\begin{array}{l}\text { Sergio Néstor } \\
\text { MOLA }\end{array}$ & $\begin{array}{l}\text { Ministerio } \\
\text { Público Fiscal }\end{array}$ & $\begin{array}{l}\text { FISCAL GENERAL ADJUNTO DE } \\
\text { LA PROCURACIÓN GENERAL DE } \\
\text { LA NACIÓN }\end{array}$ & $\begin{array}{c}\text { Decreto } \\
1193 / 2018\end{array}$ \\
\hline $\begin{array}{l}\text { Javier Ignacio } \\
\text { LORENZUTTI }\end{array}$ & $\begin{array}{l}\text { Ministerio } \\
\text { Público Fiscal }\end{array}$ & $\begin{array}{l}\text { FISCAL GENERAL ANTE } \\
\text { LA CÁMARA FEDERAL DE } \\
\text { APELACIONES EN LO CIVIL, } \\
\text { COMERCIAL Y CONTENCIOSO } \\
\text { ADMINISTRATIVO DE SAN } \\
\text { JUSTO }\end{array}$ & $\begin{array}{c}\text { Decreto } \\
1194 / 2018\end{array}$ \\
\hline $\begin{array}{l}\text { Fernando Luis } \\
\text { OVALLE }\end{array}$ & $\begin{array}{l}\text { Ministerio } \\
\text { Público de la } \\
\text { Defensa }\end{array}$ & $\begin{array}{l}\text { DEFENSOR PÚBLICO OFICIAL } \\
\text { ANTE LOS TRIBUNALES } \\
\text { ORALES EN LO CRIMINAL Y } \\
\text { CORRECCIONAL DE LA CAPITAL } \\
\text { FEDERAL, DEFENSORÍA N }{ }^{0} 13\end{array}$ & $\begin{array}{c}\text { Decreto } \\
1192 / 2018\end{array}$ \\
\hline
\end{tabular}




\begin{tabular}{|c|c|c|c|}
\hline Nombre & Organismo & Cargo & Decreto \\
\hline $\begin{array}{l}\text { Ignacio Ariel } \\
\text { SABÁS }\end{array}$ & $\begin{array}{l}\text { Ministerio } \\
\text { Público Fiscal }\end{array}$ & $\begin{array}{l}\text { FISCAL ANTE EL JUZGADO } \\
\text { FEDERAL DE PRIMERA } \\
\text { INSTANCIA DE SAN RAFAEL }\end{array}$ & $\begin{array}{c}\text { Decreto } \\
1195 / 2018\end{array}$ \\
\hline $\begin{array}{l}\text { Marina Vanesa } \\
\text { SOBERANO }\end{array}$ & $\begin{array}{l}\text { Ministerio } \\
\text { Público de la } \\
\text { Defensa }\end{array}$ & $\begin{array}{l}\text { DEFENSORA PÚBLICA OFICIAL } \\
\text { ANTE LOS TRIBUNALES } \\
\text { ORALES EN LO CRIMINAL Y } \\
\text { CORRECCIONAL DE LA CAPITAL } \\
\text { FEDERAL }\end{array}$ & $\begin{array}{c}\text { Decreto } \\
1184 / 2018\end{array}$ \\
\hline $\begin{array}{l}\text { María Inés } \\
\text { ITALIANI }\end{array}$ & $\begin{array}{l}\text { Ministerio } \\
\text { Público de la } \\
\text { Defensa }\end{array}$ & $\begin{array}{l}\text { DEFENSORA PÚBLICA } \\
\text { CURADORA DE LA DEFENSORÍA } \\
\text { GENERAL DE LA NACIÓN, } \\
\text { DEFENSORÍA PÚBLICA } \\
\text { CURADURÍA N } 3 \\
\end{array}$ & $\begin{array}{c}\text { Decreto } \\
1181 / 2018\end{array}$ \\
\hline $\begin{array}{l}\text { Sebastián Diego } \\
\text { ARGIBAY }\end{array}$ & Poder Judicial & $\begin{array}{l}\text { JUEZ DEL JUZGADO FEDERAL } \\
\text { DE PRIMERA INSTANCIA N }{ }^{\circ} 2 \\
\text { DE SANTIAGO DEL ESTERO }\end{array}$ & $\begin{array}{l}\text { Decreto } \\
6 / 2019\end{array}$ \\
\hline $\begin{array}{l}\text { Hernán Sergio } \\
\text { VIRI }\end{array}$ & Poder Judicial & $\begin{array}{l}\text { JUEZ DEL JUZGADO FEDERAL } \\
\text { DE PRIMERA INSTANCIA DE } \\
\text { GUALEGUAYCHÚ }\end{array}$ & $\begin{array}{l}\text { Decreto } \\
7 / 2019\end{array}$ \\
\hline $\begin{array}{l}\text { Ernesto } \\
\text { LUCCHELLI }\end{array}$ & Poder Judicial & $\begin{array}{l}\text { VOCAL DE LA CÁMARA } \\
\text { NACIONAL DE APELACIONES } \\
\text { EN LO COMERCIAL DE LA } \\
\text { CAPITAL FEDERAL, SALA F }\end{array}$ & $\begin{array}{l}\text { Decreto } \\
8 / 2019\end{array}$ \\
\hline $\begin{array}{l}\text { Javier SÁNCHEZ } \\
\text { SARMIENTO }\end{array}$ & Poder Judicial & $\begin{array}{l}\text { JUEZ DEL JUZGADO } \\
\text { NACIONAL EN LO CRIMINAL } \\
\text { Y CORRECCIONAL Nº } 48 \text { DE LA } \\
\text { CAPITAL FEDERAL }\end{array}$ & $\begin{array}{l}\text { Decreto } \\
\text { 9/2019 }\end{array}$ \\
\hline $\begin{array}{l}\text { Julieta } \\
\text { MATTONE }\end{array}$ & $\begin{array}{l}\text { Ministerio } \\
\text { Público de la } \\
\text { Defensa }\end{array}$ & $\begin{array}{l}\text { DEFENSORA PÚBLICA OFICIAL } \\
\text { ANTE LOS TRIBUNALES } \\
\text { ORALES EN LO CRIMINAL Y } \\
\text { CORRECCIONAL DE LA CAPITAL } \\
\text { FEDERAL, DEFENSORÍA N }{ }^{0} 18 \\
\end{array}$ & $\begin{array}{l}\text { Decreto } \\
10 / 2019\end{array}$ \\
\hline $\begin{array}{l}\text { Gabriela Mariel } \\
\text { SCOLARICI }\end{array}$ & Poder Judicial & $\begin{array}{l}\text { VOCAL DE LA CÁMARA } \\
\text { NACIONAL DE APELACIONES } \\
\text { EN LO CIVIL DE LA CAPITAL } \\
\text { FEDERAL, SALA J }\end{array}$ & $\begin{array}{c}\text { Decreto } \\
292 / 2019\end{array}$ \\
\hline
\end{tabular}




\begin{tabular}{|c|c|c|c|}
\hline Nombre & Organismo & Cargo & Decreto \\
\hline $\begin{array}{l}\text { Simón Pedro } \\
\text { BRACCO }\end{array}$ & Poder Judicial & $\begin{array}{l}\text { JUEZ DE CÁMARA DEL } \\
\text { TRIBUNAL ORAL EN LO } \\
\text { CRIMINAL FEDERAL DE } \\
\text { GENERAL ROCA }\end{array}$ & $\begin{array}{c}\text { Decreto } \\
291 / 2019\end{array}$ \\
\hline $\begin{array}{l}\text { Leonardo Jesús } \\
\text { AMBESI }\end{array}$ & Poder Judicial & $\begin{array}{l}\text { VOCAL DE LA CÁMARA } \\
\text { NACIONAL DE APELACIONES } \\
\text { DEL TRABAJO DE LA CAPITAL } \\
\text { FEDERAL, SALA X }\end{array}$ & $\begin{array}{c}\text { Decreto } \\
294 / 2019\end{array}$ \\
\hline $\begin{array}{l}\text { Beatriz Ethel } \\
\text { FERDMAN }\end{array}$ & Poder Judicial & $\begin{array}{l}\text { VOCAL DE LA CÁMARA } \\
\text { NACIONAL DE APELACIONES } \\
\text { DEL TRABAJO DE LA CAPITAL } \\
\text { FEDERAL, SALA V }\end{array}$ & $\begin{array}{c}\text { Decreto } \\
295 / 2019\end{array}$ \\
\hline $\begin{array}{l}\text { Ángel Francisco } \\
\text { ANDREU }\end{array}$ & Poder Judicial & $\begin{array}{l}\text { JUEZ DE CÁMARA DEL } \\
\text { TRIBUNAL ORAL EN LO } \\
\text { CRIMINAL FEDERAL Nº } 3 \text { DE } \\
\text { CÓRDOBA }\end{array}$ & $\begin{array}{c}\text { Decreto } \\
293 / 2019\end{array}$ \\
\hline $\begin{array}{l}\text { Facundo } \\
\text { ZAPIOLA }\end{array}$ & Poder Judicial & $\begin{array}{l}\text { JUEZ DE CÁMARA DEL } \\
\text { TRIBUNAL ORAL EN LO } \\
\text { CRIMINAL FEDERAL Nº } 3 \text { DE } \\
\text { CÓRDOBA }\end{array}$ & $\begin{array}{c}\text { Decreto } \\
298 / 2019\end{array}$ \\
\hline $\begin{array}{l}\text { Cristina Edith } \\
\text { GIORDANO }\end{array}$ & Poder Judicial & $\begin{array}{l}\text { JUEZA DE CÁMARA DEL } \\
\text { TRIBUNAL ORAL EN LO } \\
\text { CRIMINAL FEDERAL N } 3 \text { DE } \\
\text { CÓRDOBA }\end{array}$ & $\begin{array}{l}\text { Decreto } \\
297 / 2019\end{array}$ \\
\hline $\begin{array}{l}\text { Bibiana Inés } \\
\text { DÍAZ }\end{array}$ & Poder Judicial & $\begin{array}{l}\text { JUEZA DEL JUZGADO } \\
\text { NACIONAL DE PRIMERA } \\
\text { INSTANCIA DEL TRABAJO Nº53 } \\
\text { DE LA CAPITAL FEDERAL }\end{array}$ & $\begin{array}{c}\text { Decreto } \\
\text { 299/2019 }\end{array}$ \\
\hline \begin{tabular}{|l|} 
Claudia \\
Alejandra \\
FONTAIÑA \\
GONZÁLEZ \\
\end{tabular} & Poder Judicial & $\begin{array}{l}\text { JUEZA DEL JUZGADO } \\
\text { NACIONAL DE PRIMERA } \\
\text { INSTANCIA DEL TRABAJO Nº } 28 \\
\text { DE LA CAPITAL FEDERAL } \\
\end{array}$ & $\begin{array}{c}\text { Decreto } \\
296 / 2019\end{array}$ \\
\hline Carolina PRADO & Poder Judicial & $\begin{array}{l}\text { JUEZA DE CÁMARA DEL } \\
\text { TRIBUNAL ORAL EN LO } \\
\text { CRIMINAL FEDERAL N } 1 \text { DE } \\
\text { CÓRDOBA }\end{array}$ & $\begin{array}{c}\text { Decreto } \\
300 / 2019\end{array}$ \\
\hline
\end{tabular}




\begin{tabular}{|c|c|c|c|}
\hline Nombre & Organismo & Cargo & Decreto \\
\hline $\begin{array}{l}\text { José Luis } \\
\text { Alberto } \\
\text { AGUILAR }\end{array}$ & Poder Judicial & $\begin{array}{l}\text { VOCAL DE LA CÁMARA } \\
\text { FEDERAL DE APELACIONES DE } \\
\text { RESISTENCIA }\end{array}$ & $\begin{array}{c}\text { Decreto } \\
290 / 2019\end{array}$ \\
\hline $\begin{array}{l}\text { María Eugenia } \\
\text { CAPUCHETTI }\end{array}$ & Poder Judicial & $\begin{array}{l}\text { JUEZA DEL JUZGADO } \\
\text { NACIONAL EN LO CRIMINAL Y } \\
\text { CORRECCIONAL FEDERAL N }{ }^{0} 5 \\
\text { DE LA CAPITAL FEDERAL }\end{array}$ & $\begin{array}{c}\text { Decreto } \\
304 / 2019\end{array}$ \\
\hline $\begin{array}{l}\text { María Noel } \\
\text { COSTA }\end{array}$ & Poder Judicial & $\begin{array}{l}\text { JUEZA DE CÁMARA DEL } \\
\text { TRIBUNAL ORAL EN LO } \\
\text { CRIMINAL FEDERAL N } 2 \text { DE } \\
\text { CÓRDOBA }\end{array}$ & $\begin{array}{c}\text { Decreto } \\
303 / 2019\end{array}$ \\
\hline $\begin{array}{l}\text { Manuel Pablo } \\
\text { DIEZ SELVA }\end{array}$ & Poder Judicial & $\begin{array}{l}\text { VOCAL DE LA CÁMARA } \\
\text { NACIONAL DE APELACIONES } \\
\text { DEL TRABAJO DE LA CAPITAL } \\
\text { FEDERAL, SALA IV }\end{array}$ & $\begin{array}{c}\text { Decreto } \\
305 / 2019\end{array}$ \\
\hline $\begin{array}{l}\text { Alejandro } \\
\text { CABRAL }\end{array}$ & Poder Judicial & $\begin{array}{l}\text { JUEZ DE CÁMARA DEL } \\
\text { TRIBUNAL ORAL EN LO } \\
\text { CRIMINAL FEDERAL DE } \\
\text { NEUQUÉN }\end{array}$ & $\begin{array}{c}\text { Decreto } \\
321 / 2019\end{array}$ \\
\hline $\begin{array}{l}\text { Mariel Ester } \\
\text { BORRUTO }\end{array}$ & Poder Judicial & $\begin{array}{l}\text { JUEZA DEL JUZGADO FEDERAL } \\
\text { DE PRIMERA INSTANCIA DE } \\
\text { RÍO GRANDE, PROVINCIA } \\
\text { DE TIERRA DEL FUEGO, } \\
\text { ANTÁRTIDA E ISLAS DEL } \\
\text { ATLÁNTICO SUR }\end{array}$ & $\begin{array}{c}\text { Decreto } \\
319 / 2019\end{array}$ \\
\hline $\begin{array}{l}\text { Karina Gisela } \\
\text { ALONSO } \\
\text { CANDIS }\end{array}$ & Poder Judicial & $\begin{array}{l}\text { JUEZA DEL JUZGADO FEDERAL } \\
\text { DE PRIMERA INSTANCIA DE LA } \\
\text { SEGURIDAD SOCIAL N } 1 \text { DE LA } \\
\text { CAPITAL FEDERAL }\end{array}$ & $\begin{array}{c}\text { Decreto } \\
318 / 2019\end{array}$ \\
\hline $\begin{array}{l}\text { Gastón Matías } \\
\text { POLO OLIVERA }\end{array}$ & Poder Judicial & $\begin{array}{l}\text { VOCAL DE LA CÁMARA } \\
\text { NACIONAL DE APELACIONES } \\
\text { EN LO CIVIL DE LA CAPITAL } \\
\text { FEDERAL, SALA G }\end{array}$ & $\begin{array}{c}\text { Decreto } \\
320 / 2019\end{array}$ \\
\hline $\begin{array}{l}\text { Analía Graciela } \\
\text { RAMPONI }\end{array}$ & Poder Judicial & $\begin{array}{l}\text { JUEZA DEL JUZGADO FEDERAL } \\
\text { DE PRIMERA INSTANCIA DE } \\
\text { CONCORDIA }\end{array}$ & $\begin{array}{c}\text { Decreto } \\
315 / 2019\end{array}$ \\
\hline
\end{tabular}




\begin{tabular}{|c|c|c|c|}
\hline Nombre & Organismo & Cargo & Decreto \\
\hline $\begin{array}{l}\text { Santiago } \\
\text { Ricardo } \\
\text { CARRILLO }\end{array}$ & Poder Judicial & \begin{tabular}{|l|} 
JUEZ DEL JUZGADO NACIONAL \\
DE PRIMERA INSTANCIA \\
EN LO CONTENCIOSO \\
ADMINISTRATIVO FEDERAL \\
No 3 DE LA CAPITAL FEDERAL
\end{tabular} & $\begin{array}{c}\text { Decreto } \\
317 / 2019\end{array}$ \\
\hline $\begin{array}{l}\text { Nadia FLORES } \\
\text { VEGA }\end{array}$ & Poder Judicial & $\begin{array}{l}\text { JUEZA DE CÁMARA DEL } \\
\text { TRIBUNAL ORAL EN LO } \\
\text { CRIMINAL FEDERAL N } 3 \text { DE } \\
\text { SAN MARTÍN }\end{array}$ & $\begin{array}{c}\text { Decreto } \\
573 / 2018\end{array}$ \\
\hline $\begin{array}{l}\text { José Luis } \\
\text { GALMARINI }\end{array}$ & Poder Judicial & $\begin{array}{l}\text { VOCAL DE LA CÁMARA } \\
\text { NACIONAL DE APELACIONES } \\
\text { EN LO CIVIL DE LA CAPITAL } \\
\text { FEDERAL, SALA F }\end{array}$ & $\begin{array}{c}\text { Decreto } \\
583 / 2018\end{array}$ \\
\hline $\begin{array}{l}\text { Mario Eduardo } \\
\text { MARTÍNEZ }\end{array}$ & Poder Judicial & $\begin{array}{l}\text { JUEZ DE CÁMARA DEL } \\
\text { TRIBUNAL ORAL EN LO } \\
\text { CRIMINAL FEDERAL DE LA } \\
\text { RIOJA }\end{array}$ & $\begin{array}{c}\text { Decreto } \\
524 / 2019\end{array}$ \\
\hline $\begin{array}{l}\text { Jorge Ignacio } \\
\text { SOBRINO REIG }\end{array}$ & Poder Judicial & $\begin{array}{l}\text { JUEZ DEL JUZGADO NACIONAL } \\
\text { DE PRIMERA INSTANCIA EN } \\
\text { LO CIVIL No } 13 \text { DE LA CAPITAL } \\
\text { FEDERAL }\end{array}$ & $\begin{array}{c}\text { Decreto } \\
529 / 2019\end{array}$ \\
\hline $\begin{array}{l}\text { Marina Edith } \\
\text { PISACCO }\end{array}$ & Poder Judicial & \begin{tabular}{|l|} 
JUEZA DEL JUZGADO \\
NACIONAL DE PRIMERA \\
INSTANCIA DEL TRABAJO № 33 \\
DE LA CAPITAL FEDERAL \\
\end{tabular} & $\begin{array}{c}\text { Decreto } \\
525 / 2019\end{array}$ \\
\hline $\begin{array}{l}\text { Luis Ricardo } \\
\text { José SÁENZ }\end{array}$ & Poder Judicial & $\begin{array}{l}\text { JUEZ DEL JUZGADO NACIONAL } \\
\text { DE PRIMERA INSTANCIA EN } \\
\text { LO CIVIL No } 21 \text { DE LA CAPITAL } \\
\text { FEDERAL }\end{array}$ & $\begin{array}{c}\text { Decreto } \\
528 / 2019\end{array}$ \\
\hline $\begin{array}{l}\text { Ignacio Martín } \\
\text { REBAUDI } \\
\text { BASAVILBASO }\end{array}$ & Poder Judicial & $\begin{array}{l}\text { JUEZ DEL JUZGADO NACIONAL } \\
\text { DE PRIMERA INSTANCIA EN } \\
\text { LO CIVIL No } 34 \text { DE LA CAPITAL } \\
\text { FEDERAL }\end{array}$ & $\begin{array}{c}\text { Decreto } \\
527 / 2019\end{array}$ \\
\hline $\begin{array}{l}\text { María de las } \\
\text { Mercedes } \\
\text { DOMínGUEZ }\end{array}$ & Poder Judicial & $\begin{array}{l}\text { JUEZA DEL JUZGADO } \\
\text { NACIONAL DE PRIMERA } \\
\text { INSTANCIA EN LO CIVIL N } 100 \\
\text { DE LA CAPITAL FEDERAL }\end{array}$ & $\begin{array}{c}\text { Decreto } \\
526 / 2019\end{array}$ \\
\hline
\end{tabular}




\begin{tabular}{|c|c|c|c|}
\hline Nombre & Organismo & Cargo & Decreto \\
\hline $\begin{array}{l}\text { Pablo Fernando } \\
\text { MORÁN }\end{array}$ & Poder Judicial & $\begin{array}{l}\text { JUEZ DEL JUZGADO FEDERAL } \\
\text { DE PRIMERA INSTANCIA N }{ }^{0} 1 \\
\text { DE FORMOSA }\end{array}$ & $\begin{array}{c}\text { Decreto } \\
564 / 2019\end{array}$ \\
\hline $\begin{array}{l}\text { Diego } \\
\text { FERNÁNDEZ } \\
\text { MADRID }\end{array}$ & Poder Judicial & $\begin{array}{l}\text { JUEZ DEL JUZGADO NACIONAL } \\
\text { DE PRIMERA INSTANCIA DEL } \\
\text { TRABAJO N } 19 \text { DE LA CAPITAL } \\
\text { FEDERAL }\end{array}$ & $\begin{array}{c}\text { Decreto } \\
565 / 2019\end{array}$ \\
\hline $\begin{array}{l}\text { Herman } \\
\text { MENDEL }\end{array}$ & Poder Judicial & $\begin{array}{l}\text { JUEZ DEL JUZGADO NACIONAL } \\
\text { DE PRIMERA INSTANCIA DEL } \\
\text { TRABAJO N } 30 \text { DE LA CAPITAL } \\
\text { FEDERAL }\end{array}$ & $\begin{array}{c}\text { Decreto } \\
573 / 2019\end{array}$ \\
\hline $\begin{array}{l}\text { Lucrecia } \\
\text { PEDRINI }\end{array}$ & Poder Judicial & $\begin{array}{l}\text { JUEZA DEL JUZGADO } \\
\text { NACIONAL DE PRIMERA } \\
\text { INSTANCIA DEL TRABAJO N } 55 \\
\text { DE LA CAPITAL FEDERAL }\end{array}$ & $\begin{array}{c}\text { Decreto } \\
574 / 2019\end{array}$ \\
\hline $\begin{array}{l}\text { Eliana Beatriz } \\
\text { RATTA RIVAS }\end{array}$ & Poder Judicial & $\begin{array}{l}\text { JUEZA DE CÁMARA DEL } \\
\text { TRIBUNAL ORAL EN LO } \\
\text { CRIMINAL FEDERAL DE SAN } \\
\text { JUAN }\end{array}$ & $\begin{array}{c}\text { Decreto } \\
578 / 2019\end{array}$ \\
\hline $\begin{array}{l}\text { Alejandro } \\
\text { Marcos } \\
\text { GALLANDAT } \\
\text { LUZURIAGA } \\
\end{array}$ & Poder Judicial & $\begin{array}{l}\text { JUEZ DEL JUZGADO FEDERAL } \\
\text { DE PRIMERA INSTANCIA DE } \\
\text { OBERÁ }\end{array}$ & $\begin{array}{c}\text { Decreto } \\
580 / 2019\end{array}$ \\
\hline $\begin{array}{l}\text { Daniel Alejandro } \\
\text { DOFFO }\end{array}$ & Poder Judicial & $\begin{array}{l}\text { JUEZ DE CÁMARA DEL } \\
\text { TRIBUNAL ORAL EN LO } \\
\text { CRIMINAL FEDERAL DE SAN } \\
\text { JUAN }\end{array}$ & $\begin{array}{c}\text { Decreto } \\
579 / 2019\end{array}$ \\
\hline $\begin{array}{l}\text { María Gabriela } \\
\text { D`ANGELO }\end{array}$ & Poder Judicial & $\begin{array}{l}\text { JUEZA DEL JUZGADO } \\
\text { NACIONAL DE PRIMERA } \\
\text { INSTANCIA DEL TRABAJO N } 48 \\
\text { DE LA CAPITAL FEDERAL }\end{array}$ & $\begin{array}{c}\text { Decreto } \\
576 / 2019\end{array}$ \\
\hline $\begin{array}{l}\text { Fernando } \\
\text { STRASSER }\end{array}$ & Poder Judicial & $\begin{array}{l}\text { JUEZ DEL JUZGADO FEDERAL } \\
\text { DE PRIMERA INSTANCIA DE LA } \\
\text { SEGURIDAD SOCIAL N } 2 \text { DE LA } \\
\text { CAPITAL FEDERAL }\end{array}$ & $\begin{array}{c}\text { Decreto } \\
640 / 2019\end{array}$ \\
\hline
\end{tabular}

